\title{
A Review of the Impact Performance of Natural Fiber Thermoplastic Composites
}

\author{
James L. Thomason* and José Luis Rudeiros-Fernández \\ Advanced Composite Group, Department of Mechanical and Aerospace Engineering, University of Strathclyde, Glasgow, \\ United Kingdom
}

Many academic studies continue to conclude that natural fiber reinforced thermoplastic composites (NFTCs) have some potential to compete with mineral/inorganic fiber and filler reinforced composites in certain applications due to their distinctive characteristics. NFTCs are often presented as a more environmentally friendly product which may, in some cases, offer useful levels of specific strength and stiffness with an overall reduced carbon footprint. However, from an end-use composite performance viewpoint, issues with impact resistance (notched and un-notched) continue to hold back the large-scale implementation of these composites. This paper presents a review of the recent work on impact properties of NFTCs, analysing the effects of fundamental composite parameters and potential routes to improvement.

OPEN ACCESS

Edited by:

Luca Valentini,

University of Perugia, Italy

Reviewed by:

Debora Puglia

University of Perugia, Italy

Rodrigo Cercená,

Universidade do Extremo Sul

Catarinense, Brazil

*Correspondence:

James L. Thomason

james.thomason@strath.ac.uk

Specialty section:

This article was submitted to Polymeric and Composite Materials,

a section of the journal

Frontiers in Materials

Received: 13 July 2018 Accepted: 06 September 2018

Published: 27 September 2018

Citation:

Thomason $J L$ and

Rudeiros-Fernández JL (2018) A Review of the Impact Performance of

Natural Fiber Thermoplastic

Composites. Front. Mater. 5:60

doi: 10.3389/fmats.2018.00060
Keywords: natural fibers, thermoplastic composites, impact properties, glass fiber, notched impact, unnotched impact

\section{INTRODUCTION}

There has been a strong growth in the applications using glass fiber (GF) and filler reinforced thermoplastic composites during the past half century. Mass processability and high performance have allowed these composites to be successfully used over a wide range of different applications (Bledzki and Gassan, 1999). Nevertheless, the increasing pressure of finite natural resources, cost competitiveness, the large amounts of energy required in manmade fiber production, environmental regulation, and growing environment awareness of society, have driven an increasing interest in natural fiber reinforced thermoplastic composites (NFTCs). Many academic researchers argue that plant-based natural fibers (NF) can successfully compete with glass fibers in today's market because of their attractive properties, which may include low cost, low density, good specific strength properties, renewable, carbon dioxide neutrality emissions, and sustainability (Saheb and Jog, 1999; Wambua et al., 2003; Joshi et al., 2004; Goda and Cao, 2007; Faruk et al., 2014; Pickering et al., 2016). The reduced production energy of NF is especially significant when compared to GF, with claims of $\sim 82 \%$ reduction in the energy required to produce a flax-fiber mat compared to a glass-fiber mat (Holbery and Houston, 2006). The benefits of energy saving are also extended through product's lifetime in the case of applications where the energy consumption is related to weight, e.g., automotive industry. Nevertheless, a certain level of reinforcement performance is still required from NF in order to succeed in engineering composite applications. In this context, many researchers refer to the respectable level of axial modulus exhibited by some NF, which can be made to appear more attractive by comparing modulus/density ratios (Park and Balatinecz, 1997; Saheb and Jog, 1999; Wambua et al., 2003; Joshi et al., 2004; Holbery and Houston, 2006; Goda and Cao, 2007; Ashori et al., 2008; Thomason, 2009a, 2010; Faruk et al., 2014; Pickering et al., 2016). 
An interesting point about such claims is that both low density and specific performance are claimed to be advantages for NF. It should, of course, be noted that any use of specific performance comparisons precludes claiming low weight or density as an advantage for NF over GF, as this is already included in the specific performance calculation. Notwithstanding this point there is ample evidence available in the literature that NFTCs can achieve modulus values within the lower range of values offered by GFTC. However, many of the potential applications for these materials are typical lower performance of the high throughput process such as injection molding and compression molding. The performance requirements of the materials used in such application is rarely limited to modulus and will also normally include targets for strength and impact resistance.

There can be little doubt for those that are familiar with the use of $\mathrm{NF}$ as a composite reinforcement that one of the frontiers of research and development of NFTCs is to characterize, understand, and improve their poor impact performance (Faruk et al., 2014; Pickering et al., 2016).

The challenge of distilling the structure-performance relationships governing the impact strength of NFTCs (and composite materials in general) from impact test results is not limited to the material complexities but also to the variety in the tests and the methods of reporting their results. Systematic investigation of composite impact resistance is a complicated challenge since the result of an impact test is not solely dependent on material parameters but also on test configuration and sample configuration. For instance an important configuration parameter is whether or not the test sample has been notched. It is well-known that the magnitude of the unnotched impact (UI) performance of thermoplastic polymers is normally significantly higher than that of their notched impact (NI) strength. Furthermore, this difference is greatly reduced when reinforcements are incorporated into these polymers. Fibers and fillers can cause a significant reduction in the energy required for crack initiation while at the same time the use of fiber reinforcements significantly raises crack propagation resistance (Williams et al., 1973, Thomason, 2009b). Pendulum impact test methods are widely used in the industry due to their relatively low cost and rapid turnaround times. However, interpretation of the results of these simple tests in terms of the material microstructural parameters is not as advanced for composites materials in comparison to results for stiffness and strength testing. For example for the results of the commonly used Izod and Charpy pendulum impact tests following ASTM are often reported as energy lost per unit of thickness (such as $\mathrm{ft} . \mathrm{lb} /$ in or $\mathrm{J} / \mathrm{cm}$ ). However, the results may be reported as energy lost per unit cross-sectional area $(\mathrm{J} / \mathrm{m} 2$ or $\mathrm{ft} . \mathrm{lb} / \mathrm{in} 2)$. Using ISO methods the results are only based on the cross-sectional area of the specimen (at the notch in notched specimens). Comparison of impact results from different laboratories can be confused by these different reporting methods and conversion of energy per unit thickness to energy per unit area may not be possible if the sample dimensions are not also reported (and this is often the case in the literature of NFTCs). To assist the reader in better comprehending the challenge of the impact performance of NFTC when examining the results presented in the papers
TABLE 1 | Typical range of impact performance of GF-PP composites (from injection molded short fiber, through molded long fiber, to compression molded GMT) in the different units used in different standard pendulum impact test.

\begin{tabular}{llcc}
\hline & \multicolumn{3}{c}{ Test units } \\
\cline { 2 - 4 } Test & $\mathbf{J} / \mathbf{m}$ & $\mathbf{f t . l b} / \mathbf{i n}$ & $\mathbf{k J} / \mathbf{m} \wedge \mathbf{2}$ \\
\hline $\mathrm{NI}$ & $50-250$ & $1-5$ & $5-25$ \\
$\mathrm{UI}$ & $250-1,500$ & $5-30$ & $25-150$ \\
\hline
\end{tabular}

referenced in this review the range of impact performance that can be obtained from GF-Polypropylene composites is presented in Table 1 using the three different units discussed above.

Despite these complexities, it is clear that NFTCs will not be seriously considered for large volume engineering applications until the challenge of understanding and considerably improving their poor impact performance is comprehensively addressed. This paper presents a review of the recent work on the impact properties of NFTCs, analysing and discussing the effects of fundamental composite parameters and potential routes of improvement. The review has been divided in three main sections where specific issues of the impact performance are examined in terms of fiber content, fiber length, and chemical modification of both the fiber and the matrix. Each section consists of relevant subsections and discussions.

\section{FIBER CONTENT EFFECTS}

\section{Positive Correlation With Fiber Content}

Rana et al. (1998) analyzed the effect of fiber content (30-60 wt\%) in injection molded jute reinforced polypropylene (PP). The NI strength increased for increasing fiber content with a maximum value in the 50-60 wt\% range. Regarding the UI strength, the opposite trend was observed for composites which contained no adhesion promoter. In the case of UI strength, the authors attributed this trend to an increase of the probability of fiber agglomeration which could lead to stress concentration regions where less energy is required to start a crack. Mohanty et al. (2004a) analyzed the effect of fiber content (10-40 wt\%) on compression molded jute reinforced PP composites. The Izod NI strength of untreated $6 \mathrm{~mm}$ fiber reinforced PP increased with increasing fiber content from 10 to $30 \mathrm{wt} \%$ and subsequently decreased for further increase in fiber content. The authors interpreted these results as an improvement of the fiber-matrix interface at $30 \mathrm{wt} \%$ fiber content in comparison to the other fiber contents. Mohanty et al. (2004b) also explored the effect of fiber content (0-45 wt\%) on compression molded sisal reinforced PP composites. The Izod NI strength increased for increasing fiber content, reaching a maximum at $30 \mathrm{wt} \%$ fiber content. In a later study, Mohanty et al. (2006) studied the effect fiber content (0-30 wt\%) in compression molded jute reinforced HDPE. Again, an increase in the NI strength was observed when the fiber content increased up to $30 \mathrm{wt} \%$. Above this point the impact strength decreased with increasing fiber content. The authors explained the reduction of the impact strength at high 
fiber content through the poor interfacial adhesion and fiber agglomeration that produced non-uniform stress transfer.

Bledzki et al. (2007) studied the effect of fiber content (20$50 \mathrm{wt} \%)$ on injection molded abaca reinforced PP in comparison with jute and flax fiber reinforced PP. The NI strength increased with increasing fiber content from 20 to $40 \mathrm{wt} \%$ and decreased from 40 to $50 \mathrm{wt} \%$. In a later study, Bledzki et al. (2009) analyzed injection molded man-made cellulose and abaca fibers reinforced polylactide (PLA) and PP composites. All the composites were prepared with $30 \mathrm{wt} \%$ fiber content. PP based composites were evaluated with a $5 \mathrm{wt} \%$ maleated polypropylene (MAPP) content in relation to the fiber weight. At room temperature the PP-based materials gave significantly higher NI performance, whereas at $-30^{\circ} \mathrm{C}$ the PLA-based materials gave higher NI values. The results showed a clear difference between composites reinforced with abaca fiber and man-made cellulose. The authors attributed the difference to the higher aspect ratio of the cellulose and its smoother surface.

Jayaraman (2003) studied the effect of fiber content (9-38 wt\%) on compression molded sisal-PP sandwich composites. The Charpy NI strength of composites of fiber length of 10 , 20 , and $30 \mathrm{~mm}$ increased with increasing fiber content. For composites reinforced with $10 \mathrm{~mm}$ fibers, the increase was almost linear, reaching a maximum at $38 \mathrm{wt} \%$. In the case of composites reinforced with 20 and $30 \mathrm{~mm}$ fibers the maximum NI value was at $30 \mathrm{wt} \%$. Zhang et al. (2005) investigated the effect of fiber content (0-30 vol\%) on compression molded sisal fiber reinforced thermoplastic. The thermoplastic material used as matrix in this study was made from wood flour through benzylation process. The UI strength initially increased with increasing fiber content, reaching a maximum at $15 \mathrm{vol} \%$, after which the value decreased for increasing fiber content.

Oever et al. (1999) investigated the impact behavior of compression molded flax mat PP composites (20 and 40 vol\%). Results showed the UI strength increasing for increasing fiber content. Garkhail et al. (2000) investigated the effect of fiber content (10-50 vol\%) on compression molded flax fiber-matreinforced PP. The NI strength increased for increasing fiber content, reaching a plateau level at $25 \mathrm{vol} \%$. Singleton et al. (2003) investigated the effect of fiber content (10-30 vol\%) in film stacking and compression molding flax fiber mat reinforced recycled high density polyethylene (HDPE). The addition of flax fiber significantly increased the NI strength with a maximum at 10\% flax volume fraction. Bax and Müssig (2008) analyzed the effect of fiber content in injection molded flax (10-30 wt\%) and rayon (10-40 wt \%) reinforced PLA. The UI strength increased for increasing fiber content (10-30 wt\%) in the case of both fibers. In the case or rayon composites the impact strength decreased at $40 \mathrm{wt} \%$ fiber content compared with $30 \mathrm{wt} \%$ composites. It was suggested that above $30 \mathrm{wt} \%$ fiber content fiber agglomeration could reduce energy absorption due to fiber-fiber contact. John and Anandjiwala (2009) investigated the effect of fiber content $(0-40 \mathrm{wt} \%)$ in nonwoven flax reinforced PP composites. The NI strength increased with fiber content up to a maximum at 30 wt $\%$ and then decreased at $40 \mathrm{wt} \%$. To this regard, the authors identified matrix and fiber fracture, fiber matrix debonding, and fiber pull-out as the energy absorption mechanisms. They remarked that the friction between fibers at high fiber contents leads to lower impact strength.

Khalid et al. (2008) investigated the effects of $0-50 \mathrm{wt} \%$ oil palm empty fruit bunch fiber (EFBF) and the cellulose derived from $\mathrm{EFBF}$ on the mechanical properties of compression molding reinforced PP. In comparison with unreinforced PP the Izod NI strength of both composites initially decreases to a minimum at $10 \mathrm{wt} \%$. From this point, the NI strength increases with increasing fiber content. Cellulose reinforced PP showed higher impact strength. The authors attributed this to a better adhesion and compatibility between PP and cellulose, leading to higher impact strength. Bettini et al. (2010) studied the effect of fiber content (20-40 wt\%) on injection molded coir fiber reinforced PP. Composites with $20 \mathrm{wt} \%$ coir fiber and no MAPP content had lower Izod NI strength than pure PP. Nevertheless, NI strength increased for composites with higher fiber content (30 and $40 \mathrm{wt} \%$ ) obtaining higher values than pure PP. The authors explained this improvement by higher levels of energy dissipated through fiber-matrix debonding and fiber pull-out. Paul et al. (2010) investigated the effect of fiber content (0-60 wt\%) in compression molded short randomly oriented $6 \mathrm{~mm}$ banana fiber PP composites. Results showed an almost linear increase in the Charpy UI for increasing fiber content, reaching a maximum at $50 \%$ fiber content. Further increase of the fiber content led to a decrease in the UI strength. It was reported that the impact strength of composites depend on several factors, including reinforcement mechanical properties, properties of the interface and geometry of the composite. The authors remarked on the importance of the interface region regarding the impact strength of composites. The energy dissipated during fracture increases for weak interfaces due to crack propagation along the interfaces, leading to fiber-matrix debonding and therefore the generation of new surfaces. However, this statement ignores the important of a strong interface in resisting the initial crack formation which is so important to UI performance.

\section{Negative Correlation With Fiber Content}

Li et al. (2001) investigated the effect of filler content (0-40 wt\%) on injection molded sawdust reinforced recycled PP. Results showed a decrease of the NI with increasing fiber content in unmodified composites, reaching a minimum at $30 \mathrm{wt} \%$ which represented a decrease of $\sim 5 \%$ compared to the PP matrix alone. The initial addition of $5 \mathrm{wt} \%$ fiber did not significantly change the result in comparison with unreinforced recycled PP. Ashori et al. (2008) studied the effects of fiber content (0-40 wt\%) in compression molded wood fiber reinforced PP composites. Results showed that the NI strength decreased with increasing fiber content. Nourbakhsh and Ashori (2008) also studied the effect of fiber content (10-40 wt\%) in compression molded poplar fiber PP composites with $2 \mathrm{wt} \%$ MAPP as a coupling agent. Once again the Izod NI strength decreased with increasing fiber content. The authors remarked that an optimum level of interfacial of bonding is necessary for good impact strength. The authors also indicated that crack propagation occurs at the interface as a result of the poor interfacial adhesion between the hydrophilic poplar fiber and hydrophobic PP. 
Marcovich and Villar (2003) analyzed the effect of fiber content (30 and $40 \mathrm{wt} \%$ ) on compression molded wood flour reinforced linear low density polyethylene (LLDPE). The Izod NI strength decreased with increasing filler content. This effect was related to the increase of stress concentration points at fiber ends. These points could generate cracks which ultimately lead to composites fracture. At the same time, the increase in fiber content could increase the fiber agglomeration which forms high stress concentration areas where cracks could be initiated or easily propagated. Yang et al. (2004) studied the effect of fiber content $(0-40 \mathrm{wt} \%)$ on injection molded rice husk flour reinforced PP. The UI strength decreased with increasing fiber content. The same trend was observed for NI strength, which decreased linearly for increasing fiber content. In a later study, Yang et al. (2006) investigated the effect of filler content (040 wt\%) on injection molded rice-husk flour and wood flour reinforced PP. For both fillers the NI and UI strength decreased for increasing filler content. The initial addition of filler led to a significant drop in the impact properties, particularly in the case of NI and UI strength of wood flour composites and UI strength of rice husk flour composites. Czél and Kanyok (2007) studied the effect of fiber content (0-50 wt\%) on injection molded rice husk flour reinforced PP with MAPP as coupling agent. Results showed that the Izod NI strength decreased with increasing reinforcement content. The authors attributed this effect to a reduction of the deformability of the polymer due to the addition of the reinforcement. Yao et al. (2008) investigated the effect of fiber content $(0,30$, and $50 \mathrm{wt} \%)$ on compression molded wood fiber, rice straw leaf fiber, rice husk fiber, rice straw stem fiber, and rice whole straw fiber reinforced HDPE and recycled HDPE. In general terms the NI strength decreased with increasing fiber content.

Arbelaiz et al. (2005) analyzed the effect of fiber content (0-60 wt\%) on injection molded flax fiber reinforced PP. The UI strength dramatically dropped with the initial addition of fibers and decreased progressively with increasing fiber content. He et al. (2008) investigated the effect of fiber content (0$20 \mathrm{wt} \%$ ) on injection molded ramie fiber reinforced PP. The results showed that NI strength of all the composites was lower than that of the PP matrix and decreased with increasing fiber content. Li et al. (2012) studied the effect of fiber content (10-30 $\mathrm{wt} \%$ ) on injection molded ramie fiber reinforced PP. The Izod NI strength decreased almost linearly from 10 to $25 \mathrm{wt} \%$. Liu et al. (2009) investigated the effect fiber content (29-48 wt\%) on injection molded banana fiber reinforced HDPE/Nylon-6 composites which also contained 7.5 wt $\%$ maleated polyethylene coupling agent (MAPE). The NI strength of these composites decreased with increasing fiber content. Mohanty and Nayak (2010) examined the effect of fiber content (0-40 wt\%) in injection molded short-bamboo fiber reinforced HDPE. The Izod NI strength decreased with increasing fiber content. The authors attributed this behavior to the fibers causing a change from ductile to brittle fracture and increased fiber agglomeration causing high stress regions.

Oksman et al. (2009) analyzed the effect of fiber content (20$45 \mathrm{wt} \%$ ) of banana, jute, sisal, and flax reinforced PP. Composites were processed through a long fiber thermoplastic extrusion and compression molding process. The UI strength of sisal reinforced PP increased with increasing fiber content. The UI strength banana fiber composites did not vary significantly over the range of fiber contents. For jute and flax composites there was an initial slight increase in the UI strength from 20 to $35 \mathrm{wt} \%$ fiber content but then a decrease for 44 wt\%. Guo et al. (2010) analyzed the NI behavior of a large variety of injection molded NFs reinforced PP composites with MAPP as coupling agent. Results showed how difficult is to achieve uniform criteria regarding the use of coupling agents and fiber contents. The authors divided the analyzed NFs in three groups: wood fibers, agricultural fibers, and wood flour. The authors compared composites with two fiber contents (30 and $50 \mathrm{wt} \%$ ) always with $2 \mathrm{wt} \%$ MAPP. There was no unified final conclusion, as results depended on the kind of fiber.

Cicala et al. (2017) studied the Charpy UI performance of recycled injection molded hemp-PP composites containing MAPP and lignin. The initial UI performance was low $\left(5 \mathrm{~kJ} / \mathrm{m}^{2}\right)$ flat across the $0-20 \mathrm{wt} \%$ hemp fiber range. The UI values were decreased by three cycles of extrusion and injection molding. Chauhan et al. (2018) studied the effect of fiber content (0-50 wt\%) on the Izod performance (NI and UI) of injection molded bamboo fiber reinforced PP containing $5 \mathrm{wt} \%$ of MAPP. The composite NI was lower than that of PP alone at all fiber contents with an initial strong decrease (from 60 down to $20 \mathrm{~kJ} / \mathrm{m}^{2}$ ) at $10 \mathrm{wt} \%$ fiber and then an approximate linear increase with increasing fiber content (up to $27.1 \mathrm{~kJ} / \mathrm{m}^{2}$ at $50 \mathrm{wt} \%$ ). As in many other studies reviewed here the UI performance decreased significantly on initial addition of bamboo fiber (from 2.9 down to $2.1 \mathrm{~kJ} / \mathrm{m}^{2}$ ) and continued to decrease as the fiber content was increased (down to $9.3 \mathrm{~kJ} / \mathrm{m}^{2}$ at $50 \mathrm{wt} \%$ ).

\section{Discussion of Fiber Content Effects}

Due to differences in the nature of matrix materials, fibers, test conditions and number of fiber contents examined, the task of drawing conclusions or general statements from the above information is certainly challenging. Regarding the NI strength, which is related to the crack propagation phenomenon, a positive correlation between fiber content and NI strength has been observed in several studies (Rana et al., 1998; Garkhail et al., 2000; Jayaraman, 2003; Singleton et al., 2003; Mohanty et al., 2004a,b, 2006; Bledzki et al., 2007, 2009; Bax and Müssig, 2008; Khalid et al., 2008; John and Anandjiwala, 2009; Bettini et al., 2010; Guo et al., 2010; Mohanty and Nayak, 2010). According to some authors, with an increasing fiber content, the energy absorbed through the pull-out mechanism will also increase (John and Anandjiwala, 2009; Bettini et al., 2010). For some NFTCs, this mechanism was reported to be the main contributor to the total absorbed impact energy (Bledzki et al., 2009; Paul et al., 2010). Moreover, it has been reported that the stress distribution will also improve (Mohanty et al., 2006). However, in some cases, the increase in the NI properties is attributed to an improvement of the fiber-matrix interface at the optimum fiber content (Zhang et al., 2005). In the case of a positive correlation, an optimum in reinforcement content was often reported, above which the NI strength decreases. It is worth noting that such an optimum in NI is also observed with glass reinforced thermoplastic composites 
(Thomason, 2002, 2005). This observation may indicate that different mechanisms are involved in the energy absorption process. The reasons proposed for a decrease in NFTC NI at higher fiber contents included:

1) a decrease in interfacial adhesion in relation to the optimum fiber content (Mohanty et al., 2006).

2) fiber agglomeration which leads to areas of poor wetting and fiber-fiber contact regions (Mohanty et al., 2006; Bax and Müssig, 2008; John and Anandjiwala, 2009).

However, a negative correlation between fiber content and NI strength has also been reported in other many NFTC studies (Li et al., 2001, 2012; Marcovich and Villar, 2003; Yang et al., 2006; Czél and Kanyok, 2007; Ashori et al., 2008; He et al., 2008; Nourbakhsh and Ashori, 2008; Yao et al., 2008; Liu et al., 2009; Guo et al., 2010). The reasons proposed for this included:

1) a change in the nature of the fracture from ductile to brittle reduction of the deformability of the polymer (Mohanty and Nayak, 2010).

2) fiber agglomeration (Marcovich and Villar, 2003; Mohanty and Nayak, 2010).

3) increase of stress concentration points at fiber ends (Marcovich and Villar, 2003).

4) poor interfacial adhesion (Nourbakhsh and Ashori, 2008).

When analysing these different trends in relation to the NI strength the fibers aspect ratio and surface roughness are two of the main factors (Bledzki et al., 2009). In relation to the interface properties, opposing arguments were identified. It has been suggested that better fiber-matrix adhesion and compatibility will lead to higher impact strength (Mohanty et al., 2004a, 2006; Khalid et al., 2008; Nourbakhsh and Ashori, 2008). However, it has also been proposed that poor adhesion could lead to higher energy absorption (Bax and Müssig, 2008; Paul et al., 2010).

Similarly, in terms of UI strength opposing trends have been identified, with both positive (Oever et al., 1999; Zhang et al., 2005; Paul et al., 2010) and negative (Rana et al., 1998; Yang et al., 2004, 2006; Arbelaiz et al., 2005; Oksman et al., 2009). It has been reported that UI strength is related to the energy dissipated by plastic flexural deformation preceding crack initiation (Yang et al., 2006). Fiber agglomeration (Rana et al., 1998) has been also linked to a reduction of the energy required to initiate a crack due to stress concentrations and/or poorly wetted areas. As in the case of the NI strength, the nature of the matrix, fibers, and interface all appear to play a role in determining the impact strength dependence on fiber content.

\section{FIBER LENGTH EFFECTS}

Garkhail et al. (2000) investigated the effect of fiber length (3, 6 , and $25 \mathrm{~mm}$ ) and fiber content (10-50 vol\%) on compression molded flax fiber-mat-reinforced PP. The composite Charpy NI strength increased with increasing fiber length, reaching a maximum in composites with the $25 \mathrm{~mm}$ fibers. In the case of composites with MAPP (5 wt\% in relation to the polymer weight), the NI strength increased with increasing fiber length, reaching a maximum at $6 \mathrm{~mm}$, after which the values decreased. The authors attributed this effect to the decrease in the critical fiber length caused by the addition of MAPP. Certainly, in the case of composites with $25 \mathrm{~mm}$ fibers, the improvement of the interfacial interaction would result in the reduction of the critical fiber length and therefore increasing levels of fiber fracture, which would result in a decrease of the energy absorbed by fiber debonding and pull-out mechanisms. These results suggest that the NI strength of unmodified NFPP composites is controlled by debonding and pull-out mechanisms. The authors pointed out that, in order to increase the NI strength in this kind of composite, it is critical to improve fiber tensile strength to allow an increase of the energy absorbed through higher fiber length debonding and pull-out.

Jayaraman (2003) analyzed the influence of fiber length (1, $3,5,8,10,20$, and $30 \mathrm{~mm}$ ) on compression molded sisalPP sandwich composites with 25 wt\% fiber content. The NI strength of composites increased almost linearly with increasing fiber length. Mohanty et al. (2004a) analyzed the effect of fiber length $(3,6$, and $10 \mathrm{~mm})$ on compression molded jute reinforced PP composites with $30 \mathrm{wt} \%$ fiber content and $0.5 \%$ MAPP. Composites reinforced with $6 \mathrm{~mm}$ fiber produced the highest NI strength. Beg and Pickering (2008) investigated the effect of fiber length (1-3 mm) in injection molded kraft fiber reinforced PP composites with $40 \mathrm{wt} \%$ fiber content and $4 \mathrm{wt} \%$ MAPP. The Charpy NI strength increased by $\sim 10 \%$ with increasing average fiber length over the limited length range studied. It was pointed out that the increase of average fiber length could have caused an increase of the reinforcing efficiency due to increased stress transfer in longer fibers. At the same time, increasing the fiber length decreased the number of fiber ends increased which could act as crack initiation points, hence increasing the impact strength. He et al. (2008) investigated the effect of input fiber length $(3,5,8$, and $10 \mathrm{~mm})$ on injection molded ramie fiber reinforced PP with 15 wt $\%$ fiber content. The impact strength slightly decreased for increasing fiber length. The Izod NI strength of composites did not change significantly with fiber length but was significantly lower than the PP NI alone.

Rahman et al. (2017) investigated the Charpy NI and drop weight impact performance of compression molded quasiunidirectionally (i.e., using fabrics containing UD yarns of twisted fibers) flax reinforced PP. Laminates with three different fiber volume fractions $(0.31,0.4,0.5$ equivalent to $41,51,61$ $\mathrm{wt} \%)$ were produced and the NI performance was measured with the samples cut at a range $\left(0-90^{\circ}\right)$ of angles to the yarn direction. The PP grade was a high impact random copolymer. The NI performance of the composites at $0^{\circ}$ orientation increased with increasing fiber content and almost reached double that of the PP copolymer alone. Interestingly the NI values decreases significantly as the composites began to be loaded off-axis with a reduction to approximately one third of the matrix value when the impact test was carried out transverse to the yarn direction. Nordin et al. (2017) extensively studied the impact performance (Izod UI, Charpy UI, and Charpy NI) of injection molded oil palm fiber reinforced PP with 1\% MAPP. Fibers were cut and pulverized, followed by sieving to obtain three fiber size grades covering a range of what appears to be about two orders of 
magnitude in dimension from a flour up to $\sim 1 \mathrm{~mm}$ fiber length. Ultimately their results in all impact testing appeared to show little significant relevance of the size differences in the three grades of fiber. Both UI tests showed similar results of significant reduction in UI with increasing fiber content. The NI results appeared to show a minimum at $10 \mathrm{wt} \%$ fiber content. None of the composite samples exhibited higher impact performance than the unreinforced reference PP sample. Pailoor et al. (2018) studied the effect of changing the fiber length of the input jute fibers being compounded in a twin screw extruder. Fiber input was either "continuous" jute yarn or the same yarn which had been pre-chopped to $2 \mathrm{~mm}$ length. These compounds were used to produce injection molded jute reinforced PP samples with fiber contents in the range $20-40 \mathrm{wt} \%$ fiber. The PP contained 2 wt\% MAPP coupling agent. Both NI and UI Izod impact testing was carried out on these samples. NI increased with fiber content up to $30 \mathrm{wt} \%$ fiber content, at $40 \mathrm{wt} \%$ the NI showed little significant change from the $30 \mathrm{wt} \%$ samples. The samples containing MAPP exhibited lower values of NI for all fiber contents and fiber lengths. UI decreased steadily with increasing fiber content. In general the NI results were higher, but UI performance was lower, for the samples produced with continuous fiber input.

An increase in composite NI strength with increasing fiber length was reported by most length related studies (Garkhail et al., 2000; Jayaraman, 2003; Mohanty et al., 2004a; Beg and Pickering, 2008; Pailoor et al., 2018). It has been pointed out that an increase in the fiber length could lead to an improved stress transfer and reduction of high stress concentration points at fiber ends (Beg and Pickering, 2008). As in the case of fiber content dependence, it has been reported in some of the studies that there may be an optimum fiber length in some NFTC systems. If debonding and pull-out mechanisms are assumed to be main contributors to the absorbed energy (Beg and Pickering, 2008; John and Anandjiwala, 2009; Paul et al., 2010), the critical fiber length will determine the optimum fiber length.

\section{CHEMICAL MODIFICATION EFFECTS OF COMPOSITES}

\section{Compatibilizers and Coupling Agents}

Sanadi et al. (1994) analyzed the effect of different polymeric coupling agents on injection molded recycled newspaper fibers reinforced PP. Three different MAPP and one acrylic acidgrafted PP (AAPP) were used in composites with 40 wt $\%$ fiber content. A maximum 12\% increase of the Izod NI strength was achieved by the addition of MAPP) $(<0.5 \mathrm{wt} \%)$. In the case of Izod UI strength, the highest increase of $89 \%$ was reached with the addition of $6 \%$ G-3002 (MAPP). The results illustrated the low influence of the coupling agents on the NI strength (crack propagation) but a high effect on UI strength (crack initiation). The authors considered the length of the fibers to be too short for pull-out to be a dominant mechanism. The higher influence on UI strength is attributed to an improved fiber-matrix interphase that led to an enhanced opposition to crack initiation. It was pointed out that this effect is observed in composites where fiber length is under critical length. SEM observation of fracture surfaces showed a significant difference between modified and unmodified composites. Reduction of pull-out in modified composites indicated improved fiber-matrix adhesion. In a later study, Sanadi et al. (1999) explored the effect of MAPP as coupling agent and fiber content on injection molded kenaf fiber reinforced PP. Izod NI and UI strength increased for increasing fiber content in MAPP (3 wt $\%$ ) modified composites. In relation to the effect of MAPP, kenaf composites with 50 wt $\%$ fiber content were evaluated for $3 w t \%$ MAPP. Regarding the NI strength, modified, and non-modified composites showed equivalent results. On the other hand, the UI strength of the MAPP modified composites was $\sim 90 \%$ higher than nonmodified composites.

Karnani et al. (1997) studied the effect of MAPP as matrix modifier in injection molded kenaf reinforced PP. The NI strength was characterized for 3 different fiber contents for the MAPP analysis. In the case of unmodified PP the Izod NI strength decreases with increasing fiber content. The addition of MAPP improves the impact strength for all fiber contents. The results showed maximum impact strength at $20 \mathrm{wt} \%$ fiber content with the addition of $5 \mathrm{wt} \%$ MAPP, which represented an improvement of $\sim 14 \%$ over 20 wt $\%$ fiber content reinforced unmodified PP. Feng et al. (2001) investigated the effects of $3 \mathrm{wt} \%$ MAPP on injection molded kenaf reinforced composites with $50 \mathrm{wt} \%$ fiber content. The matrices used were PP and two different impact ethylene-propylene copolymers. The Izod NI and UI strength of all systems improved significantly with the addition of $3 \mathrm{wt} \%$ MAPP. The authors attributed the improvement to an improved adhesion between kenaf and matrix.

Oever et al. (1999) investigated the impact behavior of compression molded flax mat PP composites with fiber content of 20 and $40 \mathrm{vol} \%$ and an MAPP content of $3.5 \mathrm{wt} \%$. Composites with MAPP had lower average UI strength (although within the measurement error) when compared with unmodified PP composites. The author pointed out that these results suggest that fiber pull-out is the main energy absorbing mechanism due to the lower composite failure strain and the negligible amount energy absorbed by the flax fiber during fracture. Flax composites exhibited a much lower UI strength than GF composites. It was proposed that the use of elementary fibers instead of fiber bundles may increase the impact strength in NFTCs. In another paper on flax-PP, Oever et al. (2000) stated that an improvement in the bonding between fiber and matrix will not necessarily improve the properties of randomly oriented flax fiber composites due to the possibility for the failure to initiate within the fiber bundles internal structure.

Arbelaiz et al. (2005) analyzed the effect of MAPP (1-20 $w t \%)$ on injection molded flax fiber reinforced PP with $30 \mathrm{wt} \%$ fiber content. Two different kinds of MAPP were analyzed in the study, Epolene E43 and G3003. The initial addition of E43 and G3003 slightly decreased the Charpy UI strength with a maximum increase (50-70\%) in composite UI was observed at $10 \mathrm{wt} \%$ MAPP addition (in relation to fiber content). John and Anandjiwala (2009) investigated the use of Zein, a protein extracted from corn, as a coupling agent in compression molded nonwoven flax reinforced PP composites with a fiber content 
of 20-40 wt\%. A clear maximum in Charpy UI was obtained at $30 \mathrm{wt} \%$ fiber in the untreated flax composites. However, the composites with the Zein treated fibers exhibited approximately half the UI strength of the untreated fiber composites, despite giving significant increase in flexural strength. The authors assumed that the fiber matrix adhesion had been improved by the fiber treatment. Hence the pull-out of fibers was reduced and fiber fracture became the dominant failure mechanism with fiber breakage leading to lower energy absorption during impact.

Rana et al. (1998) analyzed the effect compatibilizer concentration (1-4 wt\%) in injection molded jute reinforced PP across a range (30-60 wt\%) of fiber contents. The effects of the MAPP on composite NI were negligible. However, the addition of MAPP led to a large increase of the UI strength for all fiber contents. The magnitude of this increase was apparently independent of the MAPP concentration in the $1-4 \mathrm{wt} \%$ range. Rozman et al. (2000) investigated the effect of MAPP (0-5 wt\%) on compression molded oil palm empty fruit bunch reinforced PP with 40 and 60 wt $\%$ fiber content. Addition of 3 wt $\%$ MAPP led to an increase of the UI strength (40 wt\% fiber content) of $\sim 25 \%$ over non-treated composites. Further increase in the percentage of MAPP did not increase the UI strength. The authors attributed this effect to improved fiber dispersion and increased fiber-matrix adhesion.

Bledzki et al. (2007) studied the effect MAPP (5 wt\%) on injection molded abaca reinforced PP in comparison with jute and flax fiber reinforced PP. There was no significant difference in the results with the addition of MAPP. For composites with 40 and $50 \mathrm{wt} \%$ the MAPP slightly decreased the NI strength. At $30 \mathrm{wt} \%$ fiber content, abaca reinforced PP showed higher NI strength than jute and flax composites. The addition of the MAPP did not have significant effect over the NI strength of any of the three different composites. In a later study, Bledzki et al. (2008) investigated the effects MAPP on injection molded flax fiber reinforced PP composites with $30 \mathrm{wt} \%$ fiber content. The addition of MAPP slightly decreased the NI strength. Bledzki et al. reported no significant changes in the NI strength of injection molded abaca fiber reinforced PP on adding $5 \mathrm{wt} \%$ of MAPP Bledzki et al. (2010a). also analyzed the effect of MAPP (5 wt\%) on injection molded barley husk, coconut shell and soft wood fibers reinforced PP with $40 \mathrm{wt} \%$ fiber content (Bledzki et al., 2010b). Once again the MAPP had no significant effect on the NI strength of the three types of fiber reinforced composites.

Stark (1999) explored the use of MAPP (3 wt\%) as a coupling agent in injection molded wood reinforced PP with 20 and 40 wt\% fiber content. Results suggested that MAPP retards crack initiation as the Izod UI strength increased slightly. On the other hand, Izod NI strength remained approximately the same which suggests that the MAPP did not influence the crack propagation process. Li et al. (2001) investigated the effect of filler content and addition of $5 \mathrm{wt} \%$ MAPP on injection molded sawdust reinforced recycled PP. The NI strength of MAPP modified composites increased with increasing fiber content, showing an opposing trend to non-modified PP composites. The maximum NI strength was reached at $40 \%$ fiber content with an increase of $\sim 15 \%$ over the PP matrix. The authors attributed this to a change in the energy dissipation mechanisms in the composites. Hristov et al. (2004) explored the influence of MAPP as coupling agent in compression molded wood fiber PP through instrumented impact testing. Results showed that the MAPP mainly enhanced the crack initiation stage and the elastic energy absorption. Ashori et al. (2008) studied the effects of coupling agents in compression molded wood fiber reinforced PP composites. The influence over the mechanical properties of a new coupling agent and polybutadiene isocyanate (PBNCO) was compared with MAPP. The addition of $3 \%$ of MAPP and $5 \%$ of PBNCO doubled the composite NI strength. The authors explained this through the improvement in the chemical compatibility.

Sain et al. (2005) analyzed the effect of low molecular weight maleated coupling agent on the mechanical behavior of different fibers in injection molded PP based composites with a $40 \mathrm{wt} \%$ fiber content. The NI strength of old newsprintfilled PP decreased with the addition of coupling agent and changed little with increasing concentration. The UI strength increased with increasing concentration of coupling agent. The authors attributed the improvements in the UI strength to better dispersion of the fiber due to the improved fiber wettability for increasing coupling agent content. Surprisingly, results showed that hemp fiber and kraft pulp composites have better tensile, UI and flexural properties than GF composites at the same fiber $w \mathrm{t} \%$ content (which means the NF composites contained approximately twice the volume fraction of fibers as the GF composites). The NI strength was equivalent for kraft pulp, hemp, and glass reinforced PP. It is noteworthy that there was no information given of the grade of GF utilized in the study, in particular whether the GF was PP compatible. It is further noted that the values presented for the GFPP composites are 30-50\% lower than would be expected for injection molded composites with PP compatible GF (Thomason, 2002). Beg and Pickering (2008) analyzed the effect of MAPP in injection molded kraft fiber reinforced PP composites with a 40 wt $\%$ fiber content. For composites with an average fiber length of $2.36 \mathrm{~mm}$ and, the addition of $4 \mathrm{wt} \%$ MAPP improved the NI strength by $12 \%$.

Marcovich and Villar (2003) analyzed the effect of MAPE on compression molded wood flour reinforced LLDPE with 30 and $40 \mathrm{wt} \%$ filler. The addition the MAPE significantly improved the NI strength of composites with the increase being much larger for the $30 \mathrm{wt} \%$ fiber sample. The authors explained this increase through the improved fiber-matrix compatibility and improved dispersion of the wood flour. Yang et al. (2006) analyzed the effect of MAPP as compatibilizer on injection molded rice-husk flour and wood flour reinforced PP. The addition of 3 wt $\%$ MAPP did not significantly change the NI or the UI strength. Lei et al. (2007) analyzed the effect of three different coupling agents on the mechanical properties of compression molded NF (bagasse fiber and pine flour) reinforced RHDPE at $30 \mathrm{wt} \%$ fiber content. The coupling agents evaluated were MAPE, titaniumderived mixture (TDM) and carboxylated polyethylene (CAPE). Results showed much higher impact strength in the case of RHDPE compared with virgin HDPE. The authors attributed this effect to impact modifiers that could have been added in previous processing. The NI strength of bagasse reinforced RHPDE was lower than pine reinforced RHDPE. For both fibers the NI strength was significantly lower than unreinforced 
RHDPE. For bagasse fiber composites the maximum NI strength was achieved by composites with $3 \mathrm{wt} \%$ MAPE. The addition of CAPE did not have any significant effect while the maximum improvement due to TDM was observed at $0.3 \mathrm{wt} \%$. In the case of pine fiber composites, the maximum NI strength was achieved by composites with $1.2 \mathrm{wt} \%$, representing an improvement of only $10 \%$. The addition of TDM led to a decrease of the NI strength.

Lee et al. (2009) studied the effects of MAPP (0-5 wt\%) in injection molded bamboo reinforced PP composites with 0$50 \mathrm{wt} \%$ fiber content. The Izod NI strength of the composites did not change significantly with increasing fiber content. The addition of 3 wt $\%$ MAPP raised the NI strength by $10-20 \%$ depending on fiber content. Increasing the MAPP content did not have any significant effect. Sun et al. (2009) studied the effect of fiber content (0-30 wt\%) and MAPP (5 wt\%) on the mechanical performance of injection molded sisal reinforced PP. Composite NI increased significantly with fiber content. The authors reported that composites without MAPP had slightly higher average NI strength (however the difference was within the measurement error). Guo et al. (2010) analyzed the effect of 2 wt $\%$ MAPP coupling agent in a large number of injection molded $\mathrm{NF}$ reinforced PP composites with 30 and $50 \mathrm{wt} \%$ fiber. The study of NFTP NI strength showed little significant effect of MAPP on the NI performance across the range of different fiber types considered. Hemp and flax fiber composites exhibited higher NI results without MAPP.

Mohanty and Nayak (2010) examined the effect of MAPE compatibilizer in injection molded short-bamboo fiber reinforced HDPE with 30 wt $\%$ fiber Composite NI strength increased with marginally $(+6 \%)$ on addition of the MAPE. Araujo et al. (2010) studied the effect of fiber content and coupling agent on injection molded curauá fibers reinforced HDPE composites with 20 wt $\%$ fiber content. Either MAPE or poly(ethylene-co-vinyl acetate) were added at $2 \mathrm{wt} \%$. The addition of curaruá fiber resulted in a very large reduction of both UI and NI strength compared to the polymer matrix. The addition of the coupling agents resulted in no significant change in composite NI. Only the MAPE with a higher acid group content gave any significant improvement (16\%) in composite UI. Bettini et al. (2010) studied the effect of MAPP as compatibilizer in injection molded coir fiber reinforced PP with 20 and $40 \mathrm{wt} \%$ fiber content. The addition of $4 \mathrm{wt} \%$ MAPP decreased the composite NI strength by $4-11 \%$ and the addition of $8 \mathrm{wt} \%$ MAPP decreased the composite NI strength by $9-18 \%$. The authors suggested that these results indicated an increased fiber-matrix adhesion and that the energy dissipated through pull-out decreased. Malfatti et al. (2017) studied the effect of a range of hot melt adhesive additives on the Charpy UI performance of injection molded $30 \mathrm{wt} \%$ flax reinforced PP with and without MAPP coupling agent. Their idea was to improve fiber-matrix adhesion through the addition of dendritic polyesters (DP) or thermoplastic polyurethane. The polyurethane additive had little effect on the UI performance of the composites. However, all three DP additives significantly increased UI from $\sim 10$ up to $30 \mathrm{~kJ} / \mathrm{m}^{2}$. When used in conjunction with MAPP even better results were obtained with only $1 \mathrm{wt} \%$ of DP increasing the composite UI from $12 \mathrm{~kJ} / \mathrm{m}^{2}$ to over $40 \mathrm{~kJ} / \mathrm{m}^{2}$. Interestingly despite the hypothesis of improved interfacial adhesion the DP additive gave no significant improvement in the tensile strength of the composites.

\section{Discussion}

The increase of NFTC NI strength by the addition of compatibilizer has been observed in several studies (Sanadi et al., 1994, 1999; Karnani et al., 1997; Feng et al., 2001; Li et al., 2001; Lei et al., 2007; Ashori et al., 2008; Beg and Pickering, 2008; Lee et al., 2009; Araujo et al., 2010; Guo et al., 2010; Mohanty and Nayak, 2010; Paul et al., 2010; Malfatti et al., 2017). This is often related to an increase in the fiber-matrix adhesion/compatibility, which leads to higher energy required for crack propagation (Feng et al., 2001; Marcovich and Villar, 2003; Ashori et al., 2008). Surprisingly, a similar argument has also been used to argue a decrease in the NI strength, where high fiber-matrix compatibility may lead to lower energy absorption by the fiber pull-out mechanism (John and Anandjiwala, 2009; Bettini et al., 2010; Bledzki et al., 2010a). Some studies did not report any significant changes in the NI strength (Bledzki et al., 2010a,b). At high MAPP concentrations, it has been pointed out that the NI strength could decrease due to a selfentanglement effect between the compatibilizer, resulting in fiber slippage (Rana et al., 1998). In terms of the UI strength of NFTC, the addition of compatibilizer has been reported to produce increases in several studies (Sanadi et al., 1994, 1999; Rana et al., 1998; Stark, 1999; Rozman et al., 2000; Feng et al., 2001; Sain et al., 2005; Araujo et al., 2010). Arguments often mentioned for the UI increase included an increase in fibermatrix adhesion (Rozman et al., 2000; Feng et al., 2001) and improved fiber dispersion (Rozman et al., 2000). Nevertheless, a negative correlation between compatibilizer addition and UI strength has also reported by some authors (Oever et al., 1999; Araujo et al., 2010).

In general terms, an optimum level of fiber-matrix adhesion appears to be crucial. High levels of adhesion may lead to brittle failure while low levels result in low fiber pull-out energy absorption (Sain et al., 2005). As previously discussed the fiber aspect ratio appears to be critical in determining the effect of compatibilizers (Sanadi et al., 1994, 1999; Rana et al., 1998) in NFTC impact. In systems where the fiber length is lower than critical fiber length, it has been shown that coupling agents have less influence on the NI strength or crack propagation phenomenon and more influence on the UI strength related to crack initiation (Sanadi et al., 1994, 1999; Stark, 1999; Hristov et al., 2004). Even if debonding and pull-out mechanisms are diminished by increasing fiber-matrix adhesion, the energy absorption was balanced by a tougher interphase. On the other hand, it has also been pointed out that weaker interfaces could lead to higher NI energy absorption (Bledzki et al., 2008, 2010a). In the case of filler reinforcements, lower particle size results in higher UI strength due to a lower number of stress concentrations. Furthermore, it has been pointed out that the lateral strength of natural fibers has a significant influence on the fiber pull-out length (Oever et al., 
1999). It has been suggested that the use of elementary fibers instead of fiber bundles will improve UI strength (Oever et al., 1999).

\section{Impact Modifiers}

Park and Balatinecz (1996) investigated the effect of impact modification with high impact PP (HIPP) on injection molded wood fiber reinforced PP with 10-40 wt\% fiber. Addition of 10 and $30 \%$ HIPP to the PP matrix gave no significant improvement in either Izod NI or UI. Replacement of $50 \%$ of the PP by HIPP resulted in a doubling of the NFTC NI, but still with no significant improvement in UI. UI strength of all the PP blends dramatically dropped with the addition of wood fiber. It seems likely that the NI improvement was due to toughening of the matrix which was approximately tripled by the addition of $50 \%$ HIPP. In a later study, Park and Balatinecz (1997) investigated the effects of adding EPDM rubber to injection molded wood fiber reinforced PP composites with 10-40 wt\% fiber. Addition of 10\% EPDM to the PP matrix resulted in no significant change in the NI or the UI of the NFTCs. With 30\% EPDM the NI of the composites approximately doubled along with small improvements in UI. At 50\% EPDM addition both NI and UI of the NFTCs were very much higher that the PP only NFTCs. It was noted that the 50\% EPDM-PP blends without fibers did not break during testing indicating again that the improvement in the NFTC impact performance was mainly due to the increased matrix toughness. Hristov et al. (2004) explored the influence of a poly(butadiene styrene) rubber impact modifier in compression molded wood fiber PP with $10 \mathrm{wt} \%$ fiber content. The results of instrumented impact testing showed that the crack initiation energy is low dependent on the modifiers and mainly reflects the matrix behavior. On the other hand, the impact modifier mainly influences the crack propagation and plastic energy.

Xie et al. (2002) studied the effect of $0-16$ wt\% of maleated styrene-(ethylene-co-butylene)-styrene copolymer (MA-SEBS) on injection molded sisal reinforced PP with $20 \mathrm{wt} \%$ fiber content. The Izod NI energy increased with MA-SEBS addition with an increase of $\sim 200 \%$ obtain when $16 \mathrm{wt} \%$ was blended with the PP matrix. UI performance was probed using an instrumented drop weight impact method. In the modified composites the authors assumed that fiber matrix debonding and fiber pull-out are suppressed by the compatibilization effect of the MA-SEBS rubber. They suggested that the main energy absorption mechanisms for modified composites are expected to derive from the deformation of MA-SEBS rubber particles and MA-SEBS interface between PP and sisal. Ruksakulpiwat et al. (2009) analyzed the effect of natural rubber (NR) and EPDM rubber impact modifiers on injection molded vetiver grass reinforced PP composites with 30-48 wt\% fiber content. The results showed that the Izod UI strength of the composites with NR and EPDM were still very much lower than the unreinforced PP. The effect of NR and EPDM was significant in terms of improving the UI for rubber contents above $20 \mathrm{wt} \%$.

Liu et al. (2009) investigated the effect of two different modifiers on injection molded banana fiber reinforced HDPE/Nylon- 6 composites with 39 wt $\%$ fiber content. The composite modifiers analyzed were maleic anhydride grafted styrene/ethylene-butylene/styrene triblock polymer (SEBS-gMA) and MAPE. The composite Izod NI strength increased with increasing SEBS-g-MA content. In the equivalent case of reinforced HDPE, composites had a similar behavior, the NI strength increased with increasing SEBS-g-MA content. Anuar and Zuraida (2011) studied the effect of two impact modifiers and MAPP on compression molded kenaf reinforced PP with a fiber content of $20 \mathrm{vol} \%$. The two impact modifiers analyzed were thermoplastic natural rubber (TPNR) and $\mathrm{PP} /$ ethylene-propylene-diene-monomer (PP/EPDM). A ratio of thermoplastic:elastomer of 70:30 was used for both blends. The addition of kenaf fiber significantly increased the Izod NI of the PP-TPNR and PP-PP/EPDM composites over the unreinforced polymer. Addition of MAPP to the composites further improved the Izod NI strength. The authors attributed the MAPP increase to improved interfacial adhesion that reduced polymer mobility and prevented pull-out.

\section{Discussion}

The addition of impact modifiers led to an increase of the NFTC NI strength in a number of studies (Park and Balatinecz, 1996, 1997; Xie et al., 2002; Liu et al., 2009; Anuar and Zuraida, 2011) and for UI strength positive effects have also been observed in some studies (Park and Balatinecz, 1997; Ruksakulpiwat et al., 2009). Regarding NI strength, it was suggested that there is a much higher dependency on impact modifier in comparison to fiber content effects (Park and Balatinecz, 1996). In the cases where the increased fiber-matrix compatibility leads to suppression of the fiber-matrix debonding and pull-out phenomenon and in the presence of rubber particles, the main energy absorption mechanisms are related to the deformation of these rubber particles and fiber breakage (Xie et al., 2002). Moreover, the addition of impact modifier retards crack initiation and propagation (Xie et al., 2002). This last observation seems to be in conflict with other studies, where it was pointed out that crack initiation energy has a low dependency on impact modifiers, which mainly influence crack propagation and plastic deformation energy (Hristov et al., 2004). Other studies have identified different sources of improvement, where the increased fiber-matrix interfacial adhesion from the presence of impact modifiers were thought to reduce polymer mobility and prevent pull-out leading to increased NI strength (Anuar and Zuraida, 2011). It has also been suggested that the elastic behavior of the impact modifiers leads to an increase in UI strength (Ruksakulpiwat et al., 2009).

\section{Modification and Post Treatments of Fibers and Composites}

Karnani et al. (1997) studied the effect of aminosilane as a fiber modifier and MAPP as a matrix modifier in injection molded kenaf reinforced PP with $20 \mathrm{wt} \%$ fiber content. Addition of 2 and $5 \mathrm{wt} \%$ MAPP led to an increase in composite Izod NI strength of 9 and 14\%, respectively. The silane-kenaf reinforced PP showed the highest NI strength with an improvement of $24 \%$ over unmodified kenaf PP. The authors attributed this improvement to a ductile interface and a good fiber matrix interfacial adhesion created by the long polysiloxane chains. 
Results were compared with a similar study with sisal fiber where silane modification of the fiber raised the composite NI strength by $\sim 65 \%$ (Krishnan and Narayan, 1992). Threepopnatkul et al. $(2008,2009)$ analyzed the effect of fiber content and two different silanes on injection molded pineapple leaf fiber reinforced polycarbonate. All fibers were pre-treated by $\mathrm{NaOH}$ solution and then coated with $\gamma$-aminopropyltrimethoxysilane or $\gamma$-methacryloxy propyltrimethoxysilane. The composite Izod UI strength decreased by more than $90 \%$ with the addition of pineapple leaf fiber. Composites reinforced with aminosilane treated fibers-composites produced slightly better UI results compared with the other composites. This effect was attributed to increased fiber-matrix interaction.

In an early review on the influence of the surface modification of natural fibers on composite performance Mohanty et al. (2001) make little reference to composite impact properties. Subsequently Mohanty et al. (2004a) analyzed the effect of MAPP surface modification of fibers on compression molded jute reinforced PP composites with 30 wt\% fiber content. Fibers were treated by immersion in a hot MAPP solution in toluene. The MAPP treated fiber delivered significant improvements in the composite NI performance with a maximum improvement of $30 \%$ obtained. The same authors carried out a very similar study using jute fibers with very similar findings. They showed that the Izod NI of compression molded $30 \mathrm{wt} \%$ sisal reinforced PP composites increased by up to 58\% when MAPP was solution coated onto the fibers (Mohanty et al., 2004b). Using similar techniques, in a later study, Mohanty et al. (2006) studied the effect of coating fibers with MAPE solutions on the Izod NI strength of compression molded jute reinforced HDPE with 30 wt $\%$ fiber content. A maximum improvement in NI of $28 \%$ was achieved with MAPE coated jute fibers. In all the above cases the authors suggested that this improvement was related to an increase of the interfacial adhesion between fibers and matrix.

Nair and Thomas (2003) studied interface modification in compression molded sisal reinforced polystyrene composites with 20 wt\% fiber content. Fibers were treated with benzoyl chloride, polystyrene maleic anhydride (PSMA), toluene diisocyanate, methyl trithoxy silane, and triethoxy octyl silane. Only the PSMA treatment resulted in increased Izod UI strength. The authors mistakenly state that the un-notched fracture of short-fiber thermoplastic composites is controlled by fiber pull-out. The authors suggested that the UI strength decreases as the interface strength increases which is more likely related to the energy required to initiate a crack. Rozman et al. (2002) studied the effect of chemical treatment and filler size on compression molded oil palm empty fruit bunch reinforced PP with 20, 40 , and $60 \mathrm{wt} \%$ filler content. The fibers were treated with maleic anhydride (MAH) dissolved in dimethylformamide. The composite Izod UI decreased significantly with increasing fiber content. However, the UI strength of all composites also increased significantly with $\mathrm{MAH}$ content on the fibers. The authors suggested that this UI increase was related to an improvement of the fiber-matrix adhesion. Oksman et al. (2003) analyzed the effect of triacetin as a plasticizer in compression molded flax reinforced PLA with 40 wt $\%$ fiber content. The addition of triacetin had no significant effect on Charpy UI performance at any of the concentrations studied.

$\mathrm{Wu}$ et al. (2006) examined the effect of two different compatibilizers on injection molded wood fiber reinforced PP with $10 \mathrm{wt} \%$ fiber content. They used vinyl-trimethoxy silane to modify the fiber surface and maleic anhydride grafted styreneethylene-butylene-styrene triblock copolymer (SEBS-g-MA) to modify the PP matrix. The addition of $10 \mathrm{wt} \%$ wood fiber improved the Charpy NI strength by $26 \%$. The silane pretreatment of the fibers did not significantly change the composite NI strength. On the hand, the addition of $10 \mathrm{wt} \%$ of SEBSg-MA improved the NI strength by up to $80 \%$. The authors discussed the likely toughening mechanisms operating in their materials in terms of the interfacial bond strength, fiber-matrix debonding, and matrix plastic deformation. Ruksakulpiwat et al. (2007) investigated the effect of different chemical treatments on vetiver leaves and fibers as part of injection molded vetiver PP composites. The study included a number of fiber surface modification methods. A maximum improvement of only $20 \%$ in UI was achieved through a combination of $\mathrm{NaOH}$ treatment followed by coating with vinyltrimethoxysilane.

Bledzki et al. (2008) investigated the effects of fiber acetylation on injection molded flax fiber reinforced PP composites with 30 wt $\%$ fiber content. Addition of 5 wt $\%$ of MAPP had little significant effect on the Charpy NI performance of the composites. Acetylation of the fibers resulted in a decrease in NI strength which became progressively worse with increasing acetylation. The authors suggested that this was due to a stronger interface. In a later study, Bledzki et al. (2010a) investigated the effects of different fiber treatments on injection molded abaca fiber reinforced PP with 30 wt\% fiber content. The abaca fibers were treated with the enzyme fungamix or collected naturally treated and extracted from elephant dung (NDS). Fibers treated with enzyme and NDS showed an improvement in the composite Charpy NI strength of $\sim 20$ and 10\%, respectively. He et al. (2008) investigated the effect of $\mathrm{NaOH}$ treatment of fibers on injection molded ramie fiber reinforced PP with 15 wt $\%$ fiber content. Fibers were treated with a $\mathrm{NaOH}$ solution of 5,10 , and $15 \%$ concentration. There was no significant effect of the treatment on the composite NI strength. All composites had a significantly lower NI compared to the PP matrix alone.

Saleem et al. (2008) investigated the effect of pectinase treatment and MAPP on injection molded hemp fiber reinforced PP. A significant decrease of the cross section and tensile strength of the treated fibers was observed. NI strength results were not consistent. The authors attributed such uncertainty to the complex mechanisms involved in impact strength.

Rahman et al. (2009) and Haque et al. (2010a) investigated the effect of benzene diazonium treatment of fibers on injection molded coir and abaca fiber reinforced PP with 10-30 wt\% fiber content. The Charpy NI strength increased with fiber content for all composites, reaching a plateau at $15 \mathrm{wt} \%$ for treated and non-treated fiber reinforced PP. The chemical treatment did not result in a significant improvement of composite NI strength. In a later paper, the same authors added some data on using the same treatment on coir fibers for injection molded coir reinforced PP (Rahman et al., 2009). Other than the coir 
fiber giving much lower composite NI values in comparison to abaca, exactly the same lack of significant improvement from the chemical treatment was observed. In the same vein of publishing the same data twice Haque et al. (2009, 2010b) carried out an identical study on injection molded reinforced PP with coir and palm fibers composites. Once again the coir data showed no significant effects of the benzene diazonium treatment on composite NI performance. However, with the palm fibers there was evidence of an increase of about $10 \%$ in the average NI values (outside of the confidence limits) obtained from the chemical treatment. In a later study, Haque et al. (2012) studied a twostep chemical treatment on coir fibers for injection molded coir reinforced PP with 10-25 wt\% fiber content. The chemical treatment consisted of treating the fiber first with $\mathrm{NaIO} 4$ and then with p-aminophenol. Once again the NI strength increased with increased fiber content reaching a plateau above $15 \mathrm{wt} \%$. Treated coir composites showed significantly higher NI strength with a maximum increase of $40 \%$ at $25 \mathrm{wt} \%$ fiber content. The authors attributed the improvements to higher fiber-matrix interfacial adhesion.

Rahman et al. (2008) investigated the effect of oxidation treatment of fibers and post-treatment of composites on injection molded jute fiber reinforced PP with 20-35 wt\% content of $3 \mathrm{~mm}$ long fibers. The fibers were oxidized in sodium periodate solution and some composites were also post-treated in urotropine solution. The Charpy NI strength for all the composites increased with increasing fiber content, reaching a maximum between 25 and $30 \mathrm{wt} \%$. The oxidization treatment had little significant effect on the composite NI. However, the oxidized and post-treated composites showed a $23 \%$ increase in NI over the untreated sample. The authors attributed the increase in NI strength to a coupling reaction between the oxidized jute fibers and the urotropine molecules in the composite matrix. In a virtually identical paper (which does not reference the previous paper) the same authors describe, word for word, the same experiments on jute-PP composites where the post-treatment chemical was urea. The results for the composite Charpy NI strength appear to be identical with the previous samples post-treated with urotropine (Rahman et al., 2010). Finally the same authors used this same experimental approach to investigate fiber pre-treatment with o-hydroxybenzene diazonium salt on the performance of injection molded coir reinforced PP (Islam et al., 2010). Once again the Charpy NI strength increased for increasing fiber content, reaching a plateau above $15 \mathrm{wt} \%$ fiber content. At $25 \mathrm{wt} \%$ fiber content, treated fibers reinforced composites showed an improvement of $\sim 5 \%$ (hence barely significant) over non-treated fiber composites. The authors explained this "increase" of NI strength through an improved fiber-matrix interaction. Kabir et al. (2010) continued with this approach to analyse the effects of fiber pre-treatment using $\mathrm{o}^{-}, \mathrm{m}-$, and p-hydroxybenzenediazonium salt in neutral media on injection molded jute reinforced PP with 20-35 wt\% fiber content. Despite apparently using the same procedures and techniques it was now found that the Charpy NI strength was almost independent of the composite fiber content. The various chemical treatments all had a similar effect of approximately doubling the composite NI strength compared to composites made with untreated fibers.
Li et al. (2012) studied the effect of fiber treatment with epoxy-silicone oil on injection molded ramie fiber reinforced PP with 10-30 wt $\%$ fiber content. The composite Izod NI strength decreased with increasing fiber content. However, the treated composites showed an improvement of $10-20 \%$ in Izod NI strength over non-treated composites at all fiber contents. The authors attributed this increase to an improved fiber-matrix adhesion which prevented crack propagation. Rahman et al. (2018) studied the Charpy UI performance of compression molded film stacked okra fiber reinforced PP. The fiber length was $\sim 25 \mathrm{~mm}$ and they were used either untreated or after mercerization in $5 \% \mathrm{NaOH}$ at $75^{\circ} \mathrm{C}$ for $45 \mathrm{~min}$. Composite fiber content was varied in the range $25-65 \mathrm{wt} \%$. The composites exhibited a clear maximum in performance (modulus, strength, and UI) at $45 \mathrm{wt} \%$ fiber content. The mercerized fiber consistently delivered higher UI performance. Langhorst et al. (2018) investigated the Izod NI performance of injection molded $4.8 \mathrm{~mm}$ long agave bagasse fiber reinforced PP. Fiber content was varied over the range 10-30 wt $\%$ with and without MAPP coupling agent added at $5 \mathrm{wt} \%$. Two pre-treatments of $85^{\circ} \mathrm{C}$ hot water or steam-treatment were applied to the fibers prior to composite processing. Addition of fibers reduced both the elongation at break and impact strength, but increased the stiffness of the agave composites. The compatibilizer increased the fiber matrix adhesion, but reduced impact strength. There was little significant difference in the NI performance of the composites based on the fibers with different pre-treatments. None of the composites studied achieved NI performance higher than the PP polymer alone but did exceed the performance of PP containing 20 wt $\%$ of talc. The authors concluded that in automotive applications "blue-agave PP composites have the potential to replace talc-filled PP components, resulting in a lower part density and lower overall vehicle carbon footprint."

\section{Discussion}

Various fiber treatments have successfully been applied to improve the NI strength of NFTCs. Silane treatment (Karnani et al., 1997) and maleic anhydride grafted polymer fiber treatments (Mohanty et al., 2004a,b, 2006) were suggested to improve NI due to improvement of interfacial adhesion and interface ductility. Other treatments were also successful (Wu et al., 2006; He et al., 2008; Rahman et al., 2008, 2010; Bledzki et al., 2010a; Islam et al., 2010; Kabir et al., 2010; Haque et al., 2012; Li et al., 2012) in increasing the NI properties by, according to the authors, creating more ductile (Wu et al., 2006; Islam et al., 2010; Rahman et al., 2010) and stronger fibermatrix interfaces (Rahman et al., 2008, 2010; Islam et al., 2010; Haque et al., 2012). On the other hand, it has been reported that acetylation treatments also improved interface properties and resulted in a decrease in NFTC NI (Bledzki et al., 2008). Increased UI strength of NFTCs has been reported in several studies and attributed to improved fiber dispersion (Nair and Thomas, 2003; Threepopnatkul et al., 2008, 2009) and increased fiber-matrix adhesion (Rozman et al., 2002; Ruksakulpiwat et al., 2007; Threepopnatkul et al., 2008, 2009). However, improved adhesion has also been cited as causing a decrease in NFTC UI (Nair and Thomas, 2003) caused by a suppression of 
debonding and pull-out mechanisms. Some studies did not report any significant influence (Oksman et al., 2003; Haque et al., 2009, 2010a,b; Rahman et al., 2009), or inconsistent effect (Saleem et al., 2008) of their treatments on NFTC impact performance.

Regarding the detailed effect of these treatments, it has been reported that excessive treatment time can degrade fiber mechanical properties (Mohanty et al., 2006). Applying excessive amounts of MAPE on the fibers can lead to fiber slippage which reduces composite impact performance (Mohanty et al., 2006). Furthermore, it has been suggested that an optimizing the level of interfacial adhesion is crucial in order to increase impact properties (Wu et al., 2006). Mechanisms involved in energy absorption during fracture such as matrix shear yielding could be enhanced by fiber pull-out (Wu et al., 2006). Regarding the NI strength it has been suggested that a more ductile interface could prevent the brittle failure of the interface due to the stress relaxation. Silane treatments could create a highly stiff interface that inhibited plastic deformation and ultimately lead to lower absorbed energy (Wu et al., 2006). On the other hand, in the case of UI strength, improved interfacial adhesion by $\mathrm{NaOH}$-silane treatment led to increased impact properties (Ruksakulpiwat et al., 2007). In the case of the effect of optimizing the fiber-matrix interface it is noteworthy that this argument is used by different authors to explain contradictory observations. As discussed in previous sections, the nature of both the fiber and the matrix determine the overall effect of an improved interface on the impact properties.

\section{CONCLUDING REMARKS}

The impact resistance of composite materials is a complex subject where the data often reflects the parameters of the test as much as the structure-performance relationships of the materials under test (Williams et al., 1973; Thomason, 2009b). One principal consideration of such impact test parameters is whether or not the sample under test has been pre-notched as conclusions drawn from a UI test may not necessarily be applicable to NI test results. Consequently a comprehensive characterization of the impact resistance of a composite material requires study of both NI and UI performance. Table 2 presents a summary of the papers discussed in this review ordered by fiber type, polymer type, molding process and which type of pendulum impact test was performed. One observation from this study is that the suggested comprehensive approach of characterizing both NI and UI is sadly lacking in a large volume of the literature on NFTC and statements about the absolute and relative (say to GFTC) performance is often based on a single type of test. More often than not it is the NI values for NFTCs which are reported. Since the UI testing is actually simpler to perform, as it does not require the sample notching step, one might speculate that this is because the NI performance of NFTCs is relatively less bad than that of UI performance.

The results of this review support the conclusion of Thomason (2009b) that "from a structure-performance viewpoint composite impact strength appears to be influenced by all of the same parameters as tensile strength, although to differing degrees. Notched impact data generally reflect the energy required to propagate an existing crack through the sample, whereas unnotched impact data will depend on both initiation and propagation energies." Hence UI values are normally higher than NI values for any composite material where the samples are the same configuration. The addition of reinforcement fibers to a thermoplastic matrix increases the number of potential energy absorbing mechanisms in the resultant material. The fibers also significantly enlarge the volume of material in which energy dissipation can take occur as a crack propagates through the composite. It has been proposed (Thomason and Vlug, 1996) that the energy dissipation mechanisms which may occur when a crack propagates through a discontinuous fiber reinforced composite from a surface notch may include -.

- Deformation and fracture of the matrix takes place in the area in front of the crack tip.

- Fiber-matrix interface debonding may occur as the applied load, transferred by shear to the fibers, exceeds the interface strength of the interface. Transfer of stress may still be possible to a debonded fiber via frictional forces along the interface.

- Fibers fracture will occur if the fiber stress level exceeds the local fiber strength.

- Fibers pullout will occur for debonded fibers and at the interfaces of fibers that have fractured away from the crack tip.

Which, if any, of these mechanisms predominates in the process is still an unresolved discussion and the answer may differ for the same material undergoing different test configurations (as discussed above). Thomason and Vlug (1996) and Thomason (2002) have shown that a rule of mixtures equation can be applied to model the NI strength of glass fiber reinforced polypropylene and that the NI performance is particularly dependent of fiber volume fraction and fiber aspect ratio. Consequently it is perhaps not surprising that some NFTCs in this review have achieved the lower part of the GFTC NI performance range shown in Table 1. NF with lower average fiber "diameter" (e.g., flax or hemp) and longer length (as found in mat based compression molded composites) clearly reflect higher NI performance than higher diameter fibers e.g., coir or palm) or particulates (e.g., wood, flour, sawdust) of shorter length (as found in injection molded composites).

The magnitude of the UI performance of thermoplastic polymers is normally significantly higher than that of their NI strength. This difference is often greatly reduced when reinforcements are incorporated into these polymers. Fibers and fillers can cause a significant reduction in the energy required for crack initiation while simultaneously the use of fiber reinforcements significantly raises crack propagation resistance (as discussed above). Sato et al. $(1984,1998)$ have shown that fiber-matrix debonding at the fiber tips may occur well before composite failure. These debonded regions around the fiber tips may act alone, or through multiple interactions at higher strain levels, as critical flaws where the critical dimension of these flaws is proportional to the average fiber diameter. Consequently, in composites in the normal range of fiber contents, the matrix properties only have a limited influence on the UI strength and the composite impact performance in this type of test is mainly governed by fiber and interface related mechanisms (Thomason, 2006). Reflecting on the above discussion it is possible to see how 
TABLE 2 | Overview of the papers discussed in this review ordered by fiber type, polymer type, molding process, and impact test.

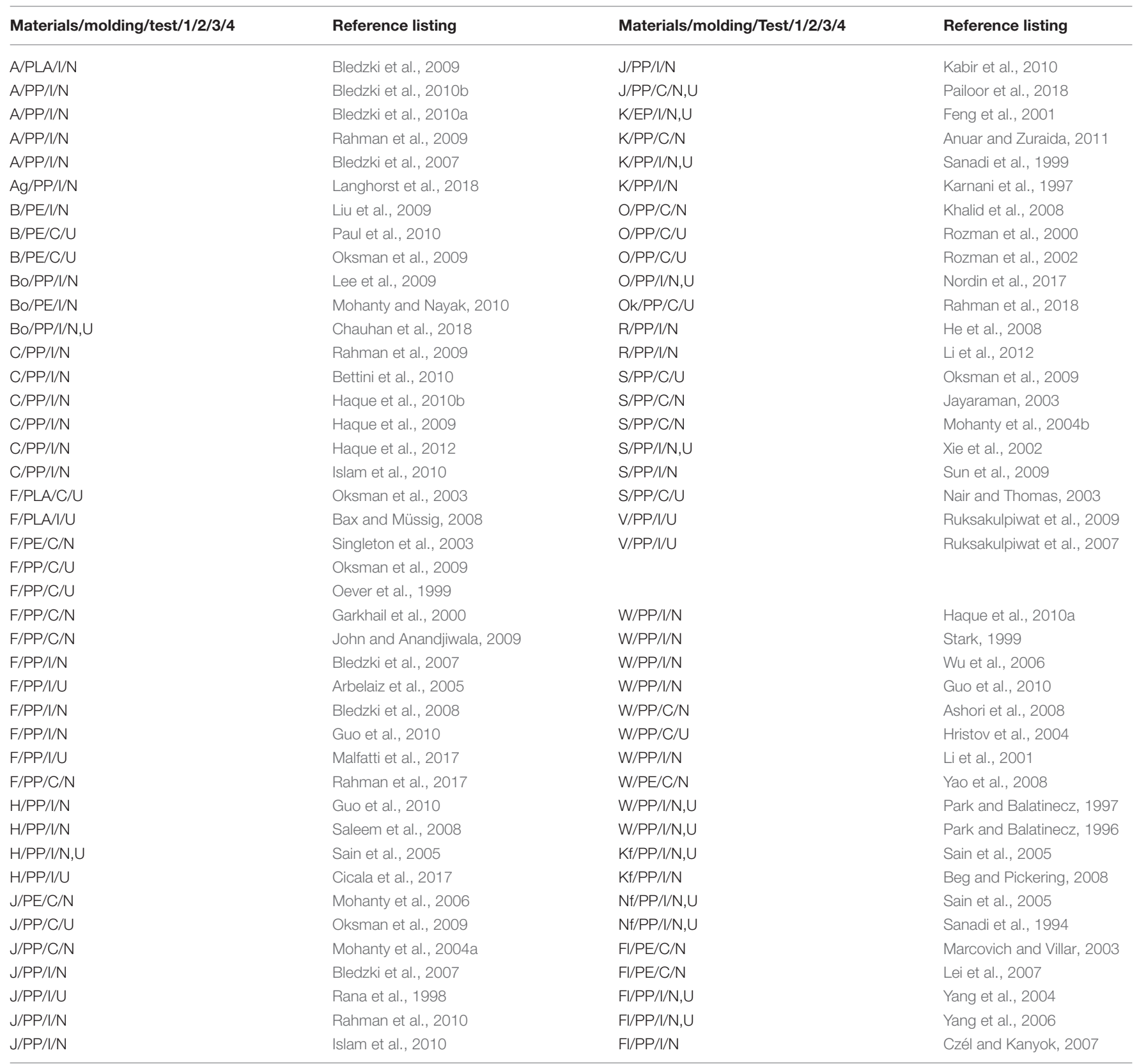

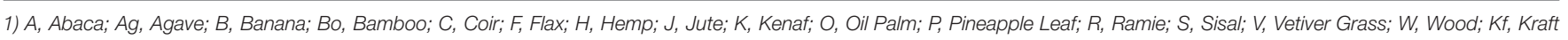
fiber; Nf, Newspaper fiber; Fl, flour (various).

2) PC, Polycarbonate; PE, Polyethylene; PLA, Polylactic acid; PP, Polypropylene; PS, Polystyrene.

3) I, Injection molded; C, Compression molded.

4) N, Notched impact; U, Unnotched impact.

the poor performance of many NFTCs in strength and strain to failure will directly translate to very low energy requirements for initiation of a critical flaw in the material and hence a poor UI performance. Low levels of interfacial adhesion to large diameter NFs or particulates will compound this poor UI performance. Furthermore, weak internal fiber structure and poor fiber dispersion will lead to regions of the material with even greater propensity to initiate flaws at lower energy levels.
Hence the effects of chemical coupling, fiber dispersion and fiber type on NFTC UI performance highlighted in this review are clarified.

As stated in the Introduction many researchers of natural fiber composites enthusiastically discuss the potential of natural fibers to replace glass fibers in semi-structural and structural composite applications. We have often commented on the research and commercial challenges that such statements pose 
to those tasked with new materials development (Thomason, 2009a, 2010; Thomason et al., 2011, 2017; Thomason and Carruthers, 2012). Not the least of such challenges is the level of reinforcement performance required from NF in order to succeed in engineering composite applications where a sufficient or high level of performance of a single mechanical performance parameter is very rarely sufficient to justify the use of a material in any particular application. Of the many balances which must be struck in materials selection the impact-modulus balance is often critical. Figures 1, 2 present an overview of the regions of impact Vs. tensile modulus (TM) covered by the literature covered in this review. These Figures are quite generic and do not claim to cover every possible combination of fiber, polymer and processing method. However, they do supply the reader with a reasonable

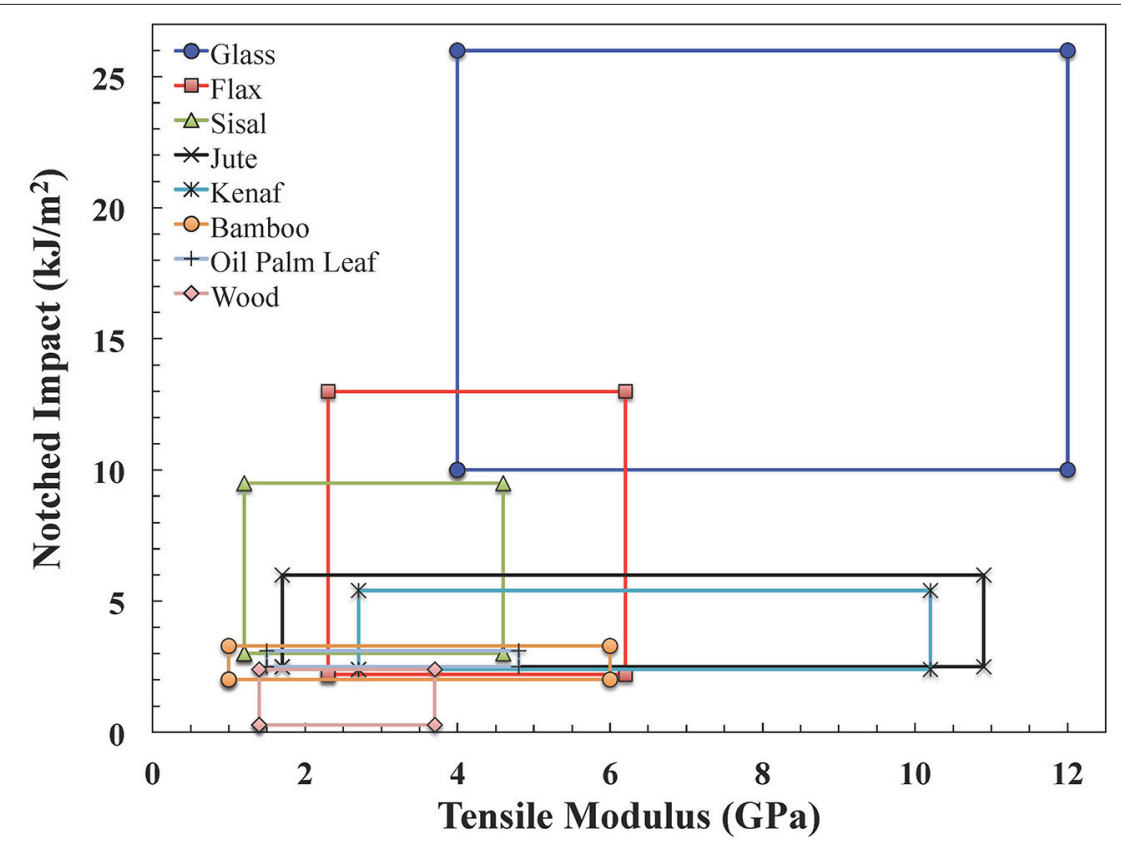

FIGURE 1 | Overview of the range of Notched Impact and Tensile Modulus covered by the papers in this review.

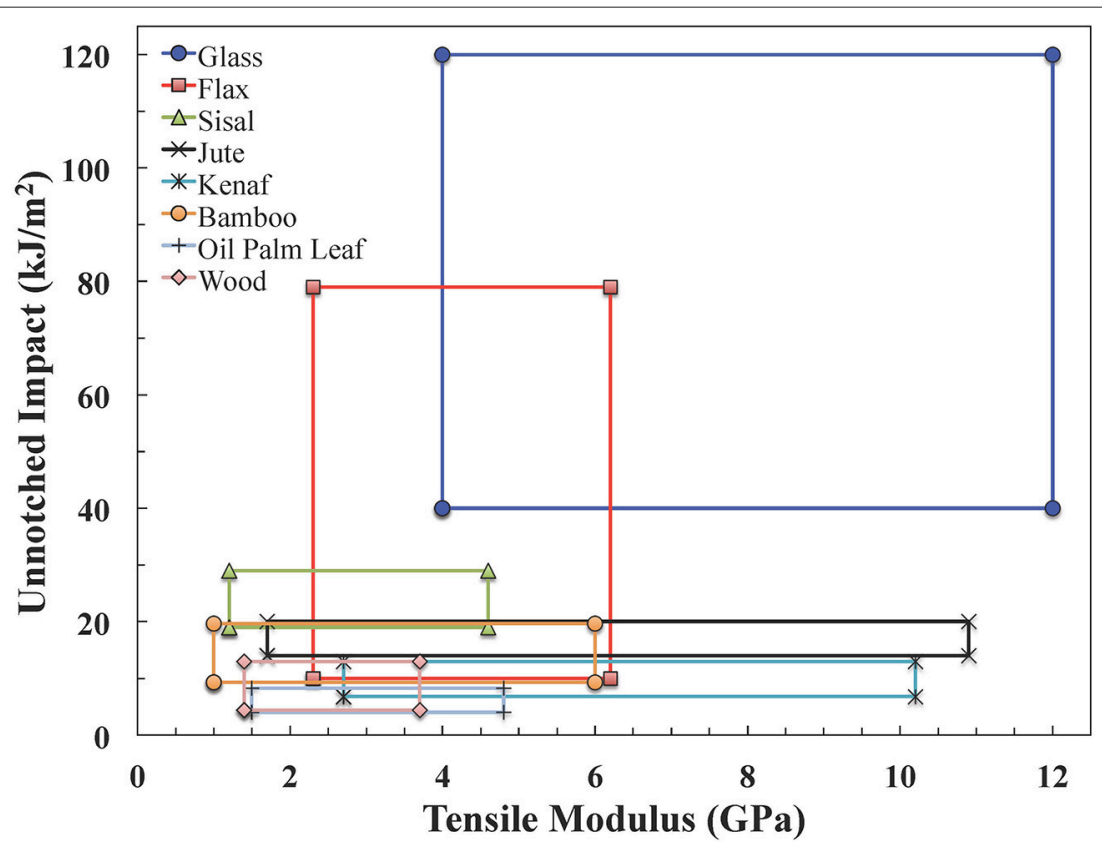

FIGURE 2 | Overview of the range of Unnotched Impact and Tensile Modulus covered by the papers in this review. 
overview of the (NI and UI) impact-modulus balance of fiber reinforced thermoplastics. It is clear from these two Figures that for materials with high levels of both modulus and impact (UI and/or NI) glass fibers are probably still the reinforcement of choice. From the papers covered in this review it appears that only flax fibers offer a possible alternative reinforcement to glass and only when relatively moderate levels of impact performance are required. Sisal fibers appear to offer the next least disadvantaged performance. It is also clear from these Figures that natural fiber reinforced thermoplastics can attain very respectable levels of tensile modulus (by using very high fiber contents). It might be argued that increasing the fiber content of flax fiber composites may increase the region of overlap with glass. However, it should be recalled that increasing fiber

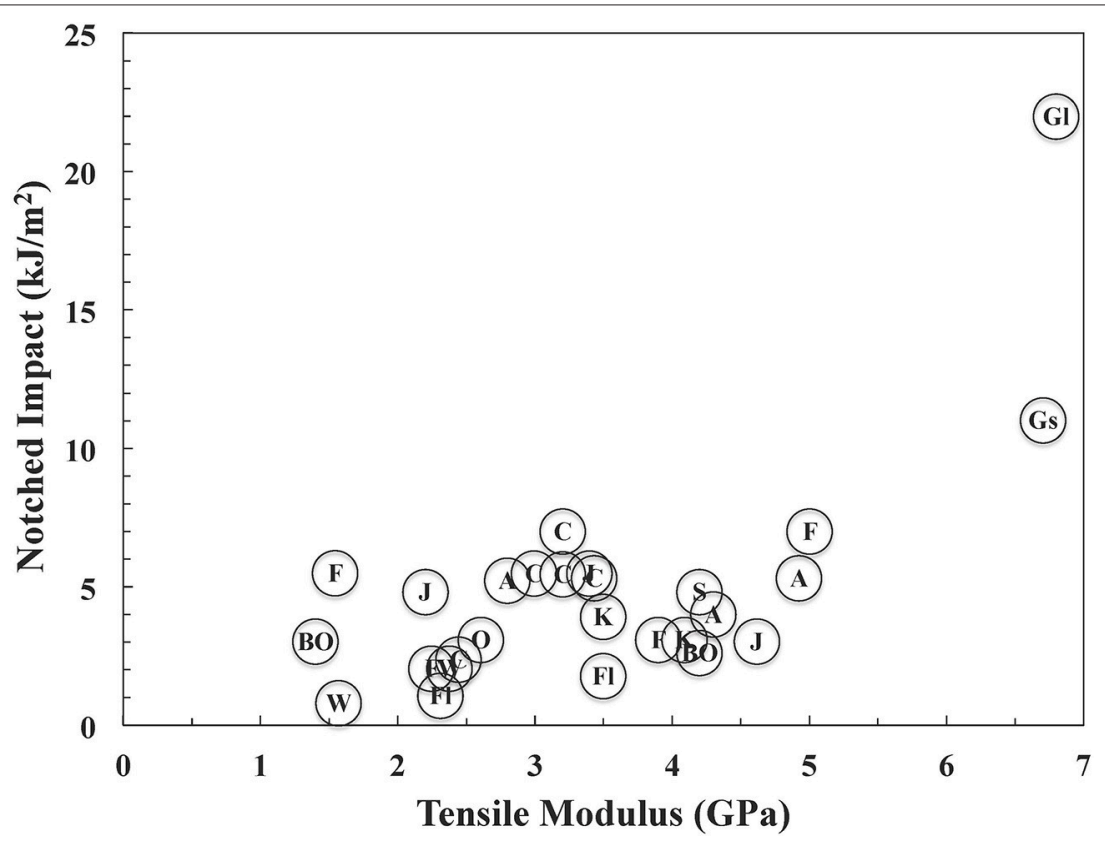

FIGURE 3 | Notched Impact Vs. Tensile Modulus for 30 wt\% fiber reinforced polypropylene covered by the papers in this review (See Table $\mathbf{2}$ for explanation of letter abbreviations).

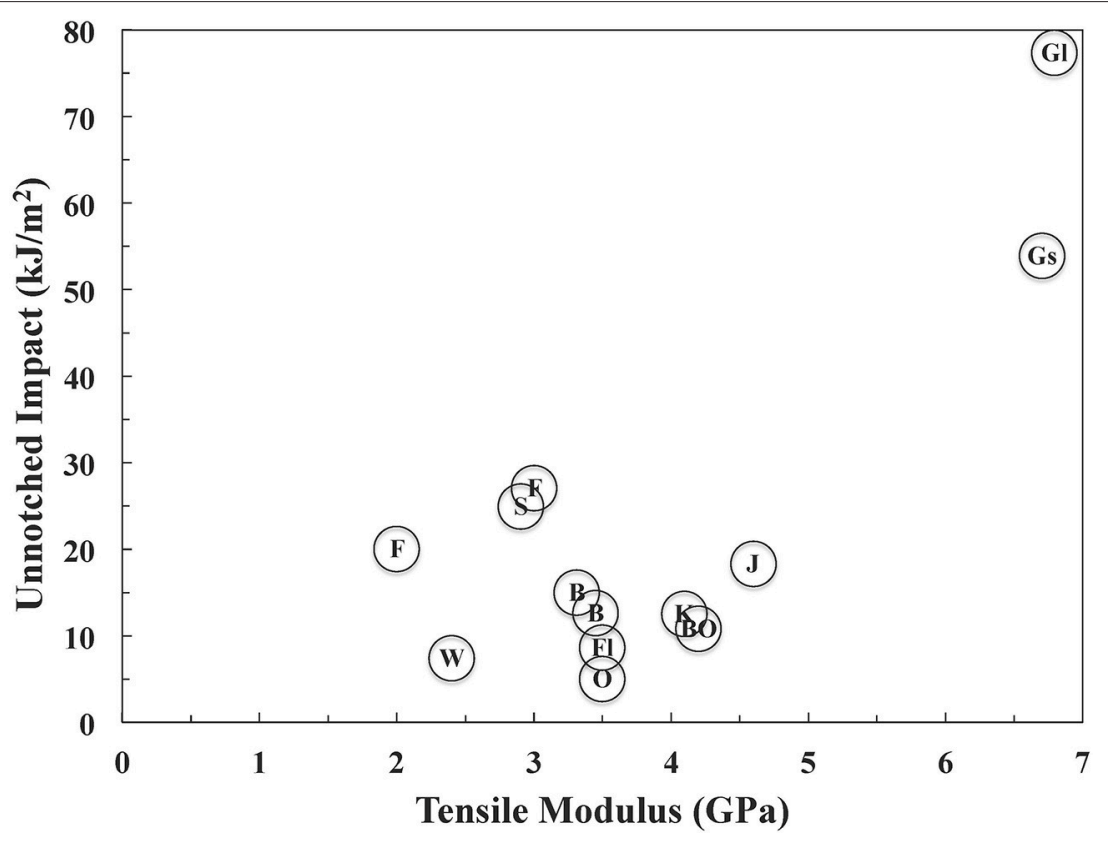

FIGURE 4 | Unnotched Impact Vs. Tensile Modulus for 30 wt\% fiber reinforced polypropylene covered by the papers in this review. 
content will most likely decrease impact performance (certainly UI).

Figures 3, 4 offer the reader a more specific comparison of glass and natural fiber performance by limiting the input range specifically to injection molded $30 \mathrm{wt} \%$ fiber reinforced polypropylene with the glass fiber results split between longfiber (pultrusion compounded) and short-fiber (extrusion compounded) performance. The data for NI-TM clearly indicate that glass fiber still outperforms natural fiber in NI performance in PP composites. Once again it appears that flax reinforcement offers the closest approach to glass performance in the lower performance short fiber applications. However, long fiber glass reinforcement of PP is still significantly higher than any natural fiber reinforced PP compound. The situation for UI performance of PP composites is still further weighted in favor of the performance of glass fiber with even short glass fiber PP compounds outperforming all natural fiber systems.

In conclusion it is therefore clear that the "Achilles' heel" of NFTCs remains their low level of impact performance, and

\section{REFERENCES}

Anuar, H., and Zuraida, A. (2011). Improvement in mechanical properties of reinforced thermoplastic elastomer composite with kenaf bast fibre. Compos. Part B 42, 462-465. doi: 10.1016/j.compositesb.2010.12.013

Araujo, J. R., Mano, B., Teixeira, G. M., Spinacé, M. A. S., and De Paoli, M.-A. (2010). Biomicrofibrilar composites of high density polyethylene reinforced with curauá fibers: mechanical, interfacial and morphological properties. Compos. Sci. Technol. 70, 1637-1644. doi: 10.1016/j.compscitech.2010.06.006

Arbelaiz, A., Fernández, B., Ramos, J. A., Retegi, A., Llano-Ponte, R., and Mondragon, I. (2005). Mechanical properties of short flax fibre bundle/polypropylene composites: influence of matrix/fibre modification, fibre content, water uptake and recycling. Compos. Sci. Technol. 65, 1582-1592. doi: 10.1016/j.compscitech.2005.01.008

Ashori, A., Nourbakhsh, A., Kokta, B. V., and Jahan-Latibari, A. (2008). Effect of a novel coupling agent, polybutadiene isocyanate, on mechanical properties of wood-fiber polypropylene composites. J. Reinf. Plast. Compos. 27, 1679-1687. doi: $10.1177 / 0731684407087377$

Bax, B., and Müssig, J. (2008). Impact and tensile properties of PLA/Cordenka and PLA/flax composites. Compos. Sci. Technol. 68, 1601-1607. doi: 10.1016/j.compscitech.2008.01.004

Beg, M., and Pickering, K. (2008). Mechanical performance of Kraft fibre reinforced polypropylene composites: influence of fibre length, fibre beating and hygrothermal ageing. Compos. Part A Appl. Sci. Manuf. 39, 1748-1755. doi: 10.1016/j.compositesa.2008.08.003

Bettini, S. H. P., Bicudo, A. B. L. C., Augusto, I. S., Antunes, L. A., Morassi, P. L., and Condotta, R. (2010). Investigation on the use of coir fiber as alternative reinforcement in polypropylene. J. Appl. Polym. Sci. 118, 2841-2848. doi: 10.1002/app.32418

Bledzki, A. K., and Gassan, J. (1999). Composites reinforced with cellulose based fibres. Prog. Polym. Sci. 24, 221-274. doi: 10.1016/S0079-6700(98)00018-5

Bledzki, A. K., Jaszkiewicz, A., and Scherzer, D. (2009). Mechanical properties of PLA composites with man-made cellulose and abaca fibres. Compos. Part A Appl. Sci. Manuf. 40, 404-412. doi: 10.1016/j.compositesa.2009.01.002

Bledzki, A. K., Mamun, A. A., and Faruk, O. (2007). Abaca fibre reinforced PP composites and comparison with jute and flax fibre PP composites. eXPRESS Polym. Lett. 1, 755-762. doi: 10.3144/expresspolymlett.2007.104

Bledzki, A. K., Mamun, A. A., Jaszkiewicz, A., and Erdmann, K. (2010a). Polypropylene composites with enzyme modified abaca fibre. Compos. Sci. Technol. 70, 854-860. doi: 10.1016/j.compscitech.2010.02.003

Bledzki, A. K., Mamun, A. A., Lucka-Gabor, M., and Gutowski, V. S. (2008). The effects of acetylation on properties of flax fibre and its polypropylene composites. eXPRESS Polym. Lett. 2, 413-422. doi: 10.3144/expresspolymlett.2008.50 in particular the low level for UI performance. Consequently we conclude that proponents of NFTCs should better focus their efforts on systematic research to understand and improve the unnotched impact performance of natural fiber composites. Alternatively the NF community could stop their somewhat unrealistic focus on replacement of glass fiber and look to less demanding applications where the performance-price envelope of NFTCs is a better fit. For instance the talc filled thermoplastic market (Langhorst et al., 2018) would seem to offer a much more realistic opportunity for NF replacement of higher density filler.

\section{AUTHOR CONTRIBUTIONS}

JR-F performed the initial literature search to identify relevant papers. JT updated the list of relevant papers. Both JT and JR-F contributed to the reviewing of the papers and the writing of the text. JT produced the Tables and was responsible for adding the concluding remarks and the arrangement and formatting of the manuscript.

Bledzki, A. K., Mamun, A. A., and Volk, J. (2010b). Barley husk and coconut shell reinforced polypropylene composites: the effect of fibre physical, chemical and surface properties. Compos. Sci. Technol. 70, 840-846. doi: 10.1016/j.compscitech.2010.01.022

Chauhan, S. S., Aggarwal, P., Venkatesh, G. S., and Abhilash, R. M. (2018). Mechanical characterization, modelling and application design of bamboo-polypropylene composites. Int. J. Plast. Technol. 22, 85-103. doi: $10.1007 /$ s12588-018-9204-0

Cicala, G., Tosto, C., Latteri, A., La Rosa, A. D., Blanco, I., Elsabbagh, A., et al. (2017). Green composites based on blends of polypropylene with liquid wood reinforced with hemp fibers: thermomechanical properties and the effect of recycling cycles. Materials 10, 998-1013. doi: 10.3390/ma10090998

Czél, G., and Kanyok, Z. (2007). MAgPP an effective coupling agent in rice husk flour filled polypropylene composites. Mater. Sci. Forum 537-538, 137-144. doi: 10.4028/www.scientific.net/MSF.537-538.137

Faruk, O., Bledzki, A. K., Fink, H. P., and Sain, M. (2014). Progress report on natural fiber reinforced composites. Macromol. Mater. Eng. 299, 9-26 doi: 10.1002/mame.201300008

Feng, D., Caulfield, D. F., and Sanadi, A. R. (2001). Effect of compatibilizer on the structure-property relationships of kenaf-fiber/polypropylene composites. Polym. Compos. 22, 506-517. doi: 10.1002/pc.10555

Garkhail, S. K., Heijenrath, R. W. H., and Peijs, T. (2000). Mechanical properties of natural-fibre-mat-reinforced thermoplastics based on flax fibres and polypropylene. Appl. Compos. Mater. 7, 351-372. doi: 10.1023/A:1026590124038

Goda, K., and Cao, Y. (2007). Research and development of fully green composites reinforced with natural fibers. J. Solid Mech. Mater. Eng. 1, 1073-1084. doi: 10.1299/jmmp.1.1073

Guo, Q., Cheng, B., Kortschot, M., Sain, M., Knudson, R., and Deng, J. (2010). Performance of long Canadian natural fibers as reinforcements in polymers. J. Reinf. Plast. Compos. 29, 3197-3207. doi: 10.1177/0731684410369722

Haque, M. M., Hasan, M., Islam, M. S., and Ali, M. E. (2009). Physicomechanical properties of chemically treated palm and coir fiber reinforced polypropylene composites. Bioresour. Technol. 100, 4903-4906. doi: 10.1016/j.biortech.2009.04.072

Haque, M. M., Islam, M. S., and Islam, M. N. (2012). Preparation and characterization of polypropylene composites reinforced with chemically treated coir. J. Polym. Res. 19:9847. doi: 10.1007/s10965-012-9847-z

Haque, M. M., Islam, M. S., Islam, M. S., Islam, M. N., and Haque, M. M. (2010a). Physicomechanical properties of chemically treated palm fiber reinforced polypropylene composites. J. Reinf. Plast. Compos. 29, 1734-1742. doi: 10.1177/0731684409341678

Haque, M. M., Rahman, R., Islam, N., Huque, M., and Hasan, M. (2010b). Mechanical properties of polypropylene composites reinforced with chemically 
treated coir and abaca fiber. J. Reinf. Plast. Compos. 29, 2253-2261. doi: 10.1177/0731684409343324

He, L. P., Tian, Y., and Wang, L. L. (2008). Study on Ramie Fiber Reinforced Polypropylene Composites (RF-PP) and its mechanical properties. Adv. Mater. Res. 41-42, 313-316. doi: 10.4028/www.scientific.net/AMR. 41-42.313

Holbery, J., and Houston, D. (2006). Natural-Fiber-reinforced polymer composites in automotive applications. JOM 58, 80-86. doi: 10.1007/s11837-006-0234-2

Hristov, R., Lach, V. N., and Grellmann, W. (2004). Impact fracture behavior of modified polypropylene/wood fiber composites. Polym. Test. 23, 581-589. doi: 10.1016/j.polymertesting.2003.10.011

Islam, M. N., Rahman, M. R., Haque, M. M., and Huque, M. M. (2010). Physico-mechanical properties of chemically treated coir reinforced polypropylene composites. Compos. Part A Appl. Sci. Manuf. 41, 192-198. doi: 10.1016/j.compositesa.2009.10.006

Jayaraman, K. (2003). Manufacturing sisal-polypropylene composites with minimum fibre degradation. Compos. Sci. Technol. 63, 367-374. doi: 10.1016/S0266-3538(02)00217-8

John, M. J., and Anandjiwala, R. D. (2009). Chemical modification of flax reinforced polypropylene composites. Compos. Part A Appl. Sci. Manuf. 40, 442-448. doi: 10.1016/j.compositesa.2009.01.007

Joshi, S. V., Drzal, L. T., Mohanty, A. K., and Arora, S. (2004). Are natural fiber composites environmentally superior to glass fiber reinforced composites? Compos. Part A Appl. Sci. Manuf. 35, 371-376. doi: 10.1016/j.compositesa.2003.09.016

Kabir, M. A., Huque, M. M., and Islam, M. R. (2010). Jute fiber reinforced polypropylene composite: effect of chemical treatment by benzenediazonium salt in neutral medium. J. Reinf. Plast. Compos. 29, 3111-3114. doi: $10.1177 / 0731684410366493$

Karnani, R., Krishnan, M., and Narayan, R. (1997). Biofiberreinforced polypropylene composites. Polym. Eng. Sci. 37, 476-483. doi: 10.1002/pen.11691

Khalid, M., Ratnam, C. T., Chuah, T. G., Ali, S., and Choong, T. S. Y. (2008). Comparative study of polypropylene composites reinforced with oil palm empty fruit bunch fiber and oil palm derived cellulose. Mater. Des. 29, 173-178. doi: 10.1016/j.matdes.2006.11.002

Krishnan, M., and Narayan, R. (1992). Compatibilization of Biomass Fibers with Hydrophobic Materials. MRS Proc. 266, 93-104. doi: 10.1557/PROC-266-93

Langhorst, A., Burkholder, J., Long, J., Thomas, R., Kiziltas, A., and Mielewski, D. (2018). Blue-agave fiber-reinforced polypropylene composites for automotive applications. BioResource 13, 820-835. doi 10.15376/biores.13.1.820-835

Lee, S., Kang, I., Park, B., Doh, G., and Park, B. (2009). Effects of filler and coupling agent on the properties of bamboo fiber-reinforced polypropylene composites. J. Reinf. Plast. Compos. 28, 2589-2604. doi: 10.1177/0731684408094070

Lei, Y., Wu, Q., Yao, F., and Xu, Y. (2007). Preparation and properties of recycled HDPE/natural fiber composites. Compos. Part A Appl. Sci. Manuf. 38, 1664-1674. doi: 10.1016/j.compositesa.2007.02.001

Li, T. Q., Ng, C. N., and Li, R. K. Y. (2001). Impact behavior of sawdust/recycled PP Composites. J. Appl. Polym. Sci. 81, 1420-1428. doi: 10.1002/app.1567

Li, X., He, L., Zhou, H., Li, W., and Zha, W. (2012). Influence of silicone oil modification on properties of ramie fiber reinforced polypropylene composites. Carbohydr. Polym. 87, 2000-2004. doi: 10.1016/j.carbpol.2011.10.023

Liu, H., Wu, Q., and Zhang, Q. (2009). Preparation and properties of banana fiberreinforced composites based on high density polyethylene (HDPE)/Nylon-6 blends. Bioresour. Technol. 100, 6088-6097. doi: 10.1016/j.biortech.2009.05.076

Malfatti, A., Steuernagel, L., and Meiners, D. (2017). Improvement of mechanical properties due to increased fibre matrix adhesion in flax fibre reinforced polypropylene. AIP Conf. Proc. 1914:070001. doi: 10.1063/1.5016728

Marcovich, N. E., and Villar, M. A. (2003). Thermal and mechanical characterization of linear low-density polyethylene/wood flour composites. J. Appl. Polym. Sci. 90, 2775-2784. doi: 10.1002/app.12934

Mohanty, A. K., Misra, M., and Drzal, L. T. (2001). Surface modifications of natural fibers and performance of the resulting biocomposites: an overview, composite interfaces, 8, 313-343. doi: 10.1163/156855401753255422

Mohanty, S., and Nayak, S. K. (2010). Short bamboo fiber-reinforced HDPE composites: influence of fiber content and modification on strength of the composite. J. Reinf. Plast. Compos. 29, 2199-2210. doi: $10.1177 / 0731684409345618$
Mohanty, S., Nayak, S. K., Verma, S. K., and Tripathy, S. S. (2004a). Effect of MAPP as a coupling agent on the performance of jute-PP Composites. J. Reinf. Plast. Compos. 23, 625-637. doi: 10.1177/0731684404032868

Mohanty, S., Nayak, S. K., Verma, S. K., and Tripathy, S. S. (2004b). Effect of MAPP as coupling agent on the performance of sisal-PP composites. J. Reinf. Plast. Compos. 23, 2047-2063. doi: 10.1177/0731684404041711

Mohanty, S., Verma, S., and Nayak, S. (2006). Dynamic mechanical and thermal properties of MAPE treated jute/HDPE composites. Compos. Sci. Technol. 66, 538-547. doi: 10.1016/j.compscitech.2005.06.014

Nair, K. C. M., and Thomas, S. (2003). Effect of interface modification on the mechanical properties of polystyrene-sisal fiber composites. Polym. Compos. 24, 332-343. doi: 10.1002/pc.10033

Nordin, A., Sakamoto, K., Azhari, H., Goda, K., Okamoto, M., Ito, H., et al. (2017). "Size effect of oil palm fibers on tensile properties of oil palm fiber-reinforced polypropylene composites," in Paper 4112, Proceedings of ICCM-21 (Xi'an).

Nourbakhsh, A., and Ashori, A. (2008). fundamental studies on wood - plastic composites: effects of fiber concentration and mixing temperature on the mechanical properties of poplar/PP composite. Polym. Compos. 29, 569-573. doi: $10.1002 / \mathrm{pc} .20578$

Oever, M. J. A., Bos, H. L., and Kemenade, M. J. J. M. (2000). Influence of the physical structure of flax fibres on the mechanical properties of flax fibre reinforced polypropylene composites. Appl. Compos. Mater. 7, 387-402. doi: 10.1023/A:1026594324947

Oever, M. J. A., Bos, H. L., and Molenveld, K. (1999). Flax fibre physical structure and its effect on composite properties: impact strength and thermo-mechanical properties. Macromol. Mater. Eng. 272, 71-76.

Oksman, K., Mathew, A. P., Långström, R., Nyström, B., and Joseph, K. (2009). The influence of fibre microstructure on fibre breakage and mechanical properties of natural fibre reinforced polypropylene. Compos. Sci. Technol. 69, 1847-1853. doi: 10.1016/j.compscitech.2009.03.020

Oksman, K., Skrifvars, M., and Selin, J.-F. (2003). Natural fibres as reinforcement in polylactic acid (PLA) composites. Compos. Sci. Technol. 63, 1317-1324. doi: 10.1016/S0266-3538(03)00103-9

Pailoor, S., Murthy, H. N. N., Hadimani, P., and Sreenivasa, T. N. (2018). Effect of chopped/continuous fiber, coupling agent and fiber ratio on the mechanical properties of injection-molded jute/polypropylene composites. J. Nat. Fibers. doi: 10.1080/15440478.2017.1410510. [Epub ahead of print].

Park, B.-D., and Balatinecz, J. J. (1996). Effects of impact modification on the mechanical properties of wood-fiber thermoplastic composites with High Impact Polypropylene (HIPP). J. Thermoplast. Compos. Mater. 9, 342-364. doi: 10.1177/089270579600900404

Park, B.-D., and Balatinecz, J. J. (1997). Mechanical properties of woodfiber/toughened lsotactic polypropylene composites. Polym. Compos. 18, 79-89. doi: $10.1002 /$ pc. 10263

Paul, S. A., Joseph, K., Mathew, G., Pothen, L. A., and Thomas, S. (2010). Preparation of polypropylene fiber/banana fiber composites by novel commingling method. Polym. Compos. 31, 816-824. doi: 10.1002/pc.20864

Pickering, K. L., Aruan Efendy, M. G., and Le, T. M. (2016). A review of recent developments in natural fibre composites and their mechanical performance. Compos. Part A 83, 98-112. doi: 10.1016/j.compositesa.2015.08.038

Rahman, A. N. M. M., Alimuzzaman, S., Khan, R. A., and Khan, M. E. (2018). Fabrication, mechanical characterization and interfacial properties of Okra fiber reinforced polypropylene composites. Int. J. Eng. Mater. Manufact. 3, 18-31. doi: 10.26776/ijemm.03.01.2018.03

Rahman, M. R., Hasan, M. M., Huque, M., and Islam, N. (2010). Physicomechanical properties of jute fiber reinforced polypropylene composites. $J$. Reinf. Plast. Compos. 29, 445-455. doi: 10.1177/0731684408098008

Rahman, M. R., Huque, M. M., Islam, M. N., and Hasan, M. (2008). Improvement of physico-mechanical properties of jute fiber reinforced polypropylene composites by post-treatment. Compos. Part A Appl. Sci. Manuf. 39, 1739-1747. doi: 10.1016/j.compositesa.2008.08.002

Rahman, M. R., Huque, M. M., Islam, M. N., and Hasan, M. (2009). Mechanical properties of polypropylene composites reinforced with chemically treated abaca. Compos. Part A Appl. Sci. Manuf. 40, 511-517. doi: 10.1016/j.compositesa.2009.01.013

Rahman, M. Z., Jayaraman, K., and Mace, B. R. (2017). Impact energy absorption of flax fiber-reinforced polypropylene composites. Polym. Compos. doi: 10.1002/pc.24486. [Epub ahead of print]. 
Rana, A. K., Mandal, A., Mitra, B. C., Jacobson, R., Rowell, R., and Banerjee, A. N. (1998). Short jute fiber-reinforced polypropylene composites: effect of compatibilizer. J. Appl. Polym. Sci. 69, 329-338. doi: 10.1002/(SICI)10974628(19980711)69:2<329::AID-APP14>3.0.CO;2-R

Rozman, H. D., Lai, C. Y., Ismail, H., and Ishak, Z. A. M. (2000). The effect of coupling agents on the mechanical and physical properties of oil palm empty fruit bunch-polypropylene composites. Polym. Int. 49, 1273-1278. doi: 10.1002/ 1097-0126(200011)49:11<1273::AID-PI469>3.0.CO;2-U

Rozman, H. D., Saad, M. J., and Ishak, Z. A. M. (2002). Flexural and impact properties of oil palm empty fruit bunch ( EFB )- polypropylene composites - the effect of maleic anhydride chemical modification of EFB. Polym. Test. 22, 335-341. doi: 10.1016/S0142-9418(02)00109-5

Ruksakulpiwat, Y., Sridee, J., Suppakarn, N., and Sutapun, W. (2009). Composites: part b improvement of impact property of natural fiber - polypropylene composite by using natural rubber and EPDM rubber. Compos. Part B 40, 619-622. doi: 10.1016/j.compositesb.2009.04.006

Ruksakulpiwat, Y., Suppakarn, N., Sutapun, W., and Thomthong, W. (2007). Vetiver-polypropylene composites: physical and mechanical properties. Compos. Part A Appl. Sci. Manuf. 38, 590-601. doi: 10.1016/j.compositesa.2006.02.006

Saheb, D. N., and Jog, J. P. (1999). Natural Fiber Polymer Composites: a review. Adv. Polym. Technol. 18, 351-363. doi: 10.1002/(SICI)10982329(199924)18:4<351::AID-ADV6>3.0.CO;2-X

Sain, M., Suhara, P., Law, S., and Bouilloux, A. (2005). Interface modification and mechanical properties of natural fiber-polyolefin composite products. J. Reinf. Plast. Compos. 24, 121-130. doi: 10.1177/0731684405041717

Saleem, Z., Rennebaum, H., Pudel, F., and Grimm, E. (2008). Treating bast fibres with pectinase improves mechanical characteristics of reinforced thermoplastic composites. Compos. Sci. Technol. 68, 471-476. doi: 10.1016/j.compscitech.2007.06.005

Sanadi, A. R., Caulfield, D. F., Stark, N. M., and Clemons, C. C. (1999). "Thermal and mechanical analysis of lignocellulosic- polypropylene composites," in 5th International Conference on Wood Plastic Composities (Madison, WI) 67-78.

Sanadi, A. R., Young, R. A., Clemons, C., and Rowell, R. M. (1994). Recycled newspaper fibers as reinforcing fillers in thermoplastics: part I-analysis of tensile and impact properties in polypropylene. J. Reinf. Plast. Compos. 13, 54-67. doi: 10.1177/073168449401300104

Sato, N., Kurauchi, T., Sato, S., and Kamigaito, O. (1984). Mechanism of fracture of short glass fibre-reinforced polyamide thermoplastic. J. Mater. Sci. 19, 1145-1152. doi: 10.1007/BF01120023

Sato, N., Kurauchi, T., Sato, S., and Kamigaito, O. (1998). Reinforcing mechanism by small diameter fiber in short fiber composites. J. Compos. Mater. 22, 850-873. doi: 10.1177/002199838802200905

Singleton, A. C. N., Baillie, C. A., Beumont, P. W. R., and Peijs, T. (2003). On the mechanical properties, deformation and fracture of a natural fibre/recycled polymer composite. Compos. Part B Eng. 34, 519-526. doi: 10.1016/S1359-8368(03)00042-8

Stark, N. M. (1999). Wood fiber derived from scrap pallets used in polypropylene composites. For. Prod. J. 49, 39-46.

Sun, Z.-Y., Han, H.-S., and Dai, G.-C. (2009). Mechanical properties of injection-molded natural fiber-reinforced polypropylene composites: formulation and compounding processes. J. Reinf. Plast. Compos. 29, 637-650. doi: $10.1177 / 0731684408100264$

Thomason, J. L. (2002). The influence of fibre length and concentration on the properties of glass fibre reinforced polypropylene: 5) Injection moulded long and short fibre PP. Compos. Part A Appl. Sci. Manuf. 33, 1641-1652. doi: $10.1016 /$ S1359-835X(02)00179-3

Thomason, J. L. (2005). The influence of fibre length and concentration on the properties of glass fibre reinforced polypropylene: 6) The properties of injection moulded long fibre PP at high fibre content. Compos. Part A Appl. Sci. Manuf. 36, 995-1003. doi: 10.1016/j.compositesa.2004.11.004

Thomason, J. L. (2006). Structure-property relationships in glass reinforced polyamide: 1) The effect of fibre content. Polym. Compos. 27, 552-562. doi: $10.1002 /$ pc.20226

Thomason, J. L. (2009a). "Why are Natural Fibers failing to deliver on composite performance?," in Proceedings of ICCM-17 (Edinburgh).
Thomason, J. L. (2009b). The influence of fibre length, diameter and concentration on the impact performance of long-glass-fibre reinforced Polyamide 6,6. Compos. Part A Appl. Sci. Manuf. 40, 114-124. doi: 10.1016/j.compositesa.2008.10.013

Thomason, J. L. (2010). Dependence of interfacial strength on the anisotropic fiber properties of jute reinforced composites. Polym. Compos. 31, 1525-1534. doi: $10.1002 /$ pc.20939

Thomason, J. L., and Carruthers, J. (2012). Natural fibre cross sectional area, variability and effects on the determination of fibre properties. J. Biobased. Mater. Bioenergy 6, 424-430. doi: 10.1166/jbmb.2012.1231

Thomason, J. L., Carruthers, J., Kelly, J., and Johnson, G. (2011). Fiber cross section determination and variability in sisal and flax and its effects on fibre performance characterisation. Compos. Sci. Technol. 71, 1008-1015. doi: 10.1016/j.compscitech.2011.03.007

Thomason, J. L., and Vlug, M. A. (1996). The influence of fibre length and concentration on the properties of glass fibre reinforced polypropylene: 4 ) Impact Properties. Composites 28A, 277-288.

Thomason, J. L., Yang, L., and Gentles, F. (2017). Characterisation of the anisotropic thermoelastic properties of natural fibres for composite reinforcement. Fibers 5:36. doi: 10.3390/fib5040036

Threepopnatkul, P., Kaerkitcha, N., and Athipongarporn, N. (2008). Polycarbonate with pineapple leaf fiber to produce functional composites. Adv. Mater. Res. 47-50, 674-677. doi: 10.4028/www.scientific.net/AMR.47-50.674

Threepopnatkul, P., Kaerkitcha, N., and Athipongarporn, N. (2009). Effect of surface treatment on performance of pineapple leaf fiberpolycarbonate composites. Compos. Part B Eng. 40, 628-632. doi: 10.1016/j.compositesb.2009.04.008

Wambua, P., Ivens, J., and Verpoest, I. (2003). Natural fibres: can they replace glass in fibre reinforced plastics? Compos. Sci. Technol. 63, 1259-1264. doi: 10.1016/S0266-3538(03)00096-4

Williams, T., Allen, G., and Kaufman, M. N. (1973). The impact strength of fibre composites. J. Mat. Sci. 8, 1765-1787. doi: 10.1007/BF02403530

Wu, J., Yu, D., Chan, C.-M., Kim, J., and Mai, Y.-W. (2006). Effect of fiber pretreatment condition on the interfacial strength and mechanical properties of wood fiber/PP composites. J. Appl. Polym. Sci. 76, 1000-1010. doi: 10.1002/ (SICI)1097-4628(20000516)76:7<1000::AID-APP3>3.0.CO;2-X

Xie, X. L., Fung, K. L., Li, R. K. Y., Tjong, S. C., and Mai, Y.-W. (2002). Structural and mechanical behavior of polypropylene/ maleated styrene-(ethylene-cobutylene)-styrene/sisal fiber composites prepared by injection molding. J. Polym. Sci. Part B Polym. Phys. 40, 1214-1222. doi: 10.1002/polb.10175

Yang, H.-S., Kim, H.-J., Son, J., Park, H.-J., Lee, B.-J., and Hwang, T.-S. (2004). Rice-husk flour filled polypropylene composites; mechanical and morphological study. Compos. Struct. 63, 305-312. doi: 10.1016/S0263-8223(03)00179-X

Yang, H.-S., Wolcott, M. P., Kim, H.-S., Kim, S., and Kim, H.-J. (2006). Properties of lignocellulosic material filled polypropylene bio-composites made with different manufacturing processes. Polym. Test. 25, 668-676. doi: 10.1016/j.polymertesting.2006.03.013

Yao, F., Wu, Q., Lei, Y., and Xu, Y. (2008). Rice straw fiber-reinforced high-density polyethylene composite: effect of fiber type and loading. Ind. Crops Prod. 28, 63-72. doi: 10.1016/j.indcrop.2008.01.007

Zhang, M., Rong, M., and Lu, X. (2005). Fully biodegradable natural fiber composites from renewable resources: all-plant fiber composites. Compos. Sci. Technol. 65, 2514-2525. doi: 10.1016/j.compscitech.2005.06.018

Conflict of Interest Statement: The authors declare that the research was conducted in the absence of any commercial or financial relationships that could be construed as a potential conflict of interest.

Copyright (C) 2018 Thomason and Rudeiros-Fernández. This is an open-access article distributed under the terms of the Creative Commons Attribution License (CC BY). The use, distribution or reproduction in other forums is permitted, provided the original author(s) and the copyright owner(s) are credited and that the original publication in this journal is cited, in accordance with accepted academic practice. No use, distribution or reproduction is permitted which does not comply with these terms. 